\title{
1 Isostasy, Flexure, and Dynamic Topography
}

3 Zohar Gvirtzman ${ }^{1,2}$, Claudio Faccenna ${ }^{3}$, Thorsten W. Becker ${ }^{4}$

4

5 1. Geological Survey of Israel, Jerusalem, Israel (corresponding author)

6 2. Institute of Earth Sciences, Hebrew University, Jerusalem, Israel

7 3. Dipartimento Scienze, Università Roma TRE, Rome, Italy

4. Department of Earth Sciences, University of Southern California, Los Angeles, California, USA

Contact details for corresponding authors: Phone: 972-2-5314269; Fax: 972-2-5380688; Zohar@gsi.gov.il

\section{Abstract}

12 A fundamental scientific question is what controls Earth's topography. Although the theoretical

13 principles of isostasy, flexure, and dynamic topography are widely discussed, the parameters needed to

14 apply these principles are frequently not available. Isostatic factors controlling lithospheric buoyancy are

15 frequently uncertain and non-isostatic factors, such as lithospheric bending towards subduction zones

16 and dynamic topography, are hard to distinguish. The question discussed here is whether a set of simple

17 rules that relate topography to lithospheric structure in various tectonic environments can be deduced

18 in a way that missing parameters can be approximated; or does each area behave differently, making

19 generalizations problematic. We contribute to this issue analyzing the Asia-Africa-Arabia-Europe domain

20 following a top-down strategy. We compile a new crustal thickness map and remove the contribution of

21 the crust from the observed elevation. Then, the challenge is to interpret the residual topography in

22 terms of mantle lithosphere buoyancy and dynamics. Based on systematic relationships between 
23 tectonic environments and factors controlling topography, we argue that crustal buoyancy and mantle

24 lithospheric density can be approximated from available geological data and that regions near mantle upwelling or downwelling are easily identified by their extreme residual topography. Yet, even for other areas, calculating lithospheric thickness from residual topography is problematic, because distinguishing

27 variations in mantle lithosphere thickness from sub-lithospheric dynamics is difficult. Fortunately, the area studied here provides an opportunity to examine this issue. Based on the conjunction between the Afar Plume and the mid-ocean ridge in the nearby Gulf of Aden and southern Red Sea, we constrain the maximal amplitude of dynamic topography to $\sim 1 \mathrm{~km}$. This estimate is based on a narrow definition of dynamic topography that only includes sub-lithospheric processes and using mid-ocean ridges as reference, where mantle lithosphere buoyancy is zero.

Keywords: Topography; Isostasy; Dynamic topography; Crust; Lithosphere; Middle East;

\section{Introduction}

A fundamental question in earth sciences is what controls the topography of the Earth's surface. Despite the basic observation that changes in topography are generally accompanied by changes in crustal

37 thickness (e.g., Heiskanen and Vening-Meinesz, 1958) that supports the paradigm of isostasy (Airy, 1855; correlation (cf. Zoback and Mooney, 2003; Fig. 1). The reason for that is that the principle of isostasy does not apply to a crust floating on lava, as envisioned by Airy (1985), but to a relatively hard

41 lithosphere floating on viscid asthenosphere. In other words, the modern paradigm of isostasy implies

42 that topography depends on lithospheric buoyancy, which depends both on the crust and on the mantle 43 lithosphere (ML) (e.g., Thompson and Talawani, 1964; Haxby and Turcotte, 1978; Davis, 1979;

44 Lachenbruch and Morgan, 1990). 
Other exceptions from a simple Airy-type model are narrow topographic loads that are not accompanied by local crustal thickening. These loads are supported by the strength of the lithosphere that does not bend easily (e.g., Watts, 2001, and references therein). In other words, narrow topographic loads do not cause local sinking of the crust into the mantle or local sinking of the lithosphere into the asthenosphere, but produce a gentle flexure spreading over wide areas. Accordingly, isostatic equilibrium is usually maintained regionally over distances of $100-200 \mathrm{~km}$, which is commonly the flexural wavelength of the lithosphere (e.g., Watts, 2001). In cases of cold and strong plates, flexure is considerably wider, particularly, in foreland and forearc basins (e.g., the north Indian Plate bending towards the Himalayas) that are strongly pulled down by far-off subducting slabs (Royden, 1993; Gvirtzman and Nur, 1999, 2001).

Another important process influencing Earth's topography on a scale of hundreds of kilometers is dynamic topography, which is a term that is used differently in the literature, but shall here indicate surface undulations caused by present-day mantle flow (e.g., Hager et al., 1985; Cazenave, et al., 1989; Colin and Fleitout, 1990; Gurnis, 1993; Forte et al., 1993; LeStunff and Ricard, 1995; Thoraval, 1995; Christensen, 1998; Lithgow-Bertelloni and Silver, 1998; Gurnis et al., 1998; Daradich et al., 2003; Forte et al., 2007; Faccenna and Becker, 2010; Moucha and Forte 2011; Becker et al., 2014). In this term dynamic refers to moving mass anomalies unlike isostasy that refers to quasi-static mass anomalies. Note, however, that whether or not lithospheric-scale processes, such as small scale convection in the thermal boundary layer and cooling of plates as they move away from spreading centers, are included in dynamic topography, is controversial (e.g., Gurnis, 1993; Forte et al, 1993; Flament et al., 2013; Becker et al., 2014; Faccenna et al., 2014a). Here we use a narrow definition of dynamic topography that only includes sub-lithospheric processes (e.g., Le Stunff and Ricard, 1995; Panasyuk and Hager, 2000; Flament et al., 2013). Accordingly, lateral variations in lithospheric thickness are considered here isostatic though its deformation is dynamic (e.g., Faccenna et al., 2014b). 
69 Topography of a certain region hence depends on quite a few factors controlling the buoyancy of the

70 lithosphere (density and thickness of the crust and $\mathrm{ML}$ ); the strength of the lithosphere (temperature,

71 composition, etc.); the existence of adjacent loads that may be a few hundred km away (subducting

72 slabs); and on many other factors controlling mantle dynamics. Hence, the ability to generate a simple

73 basic law for a fundamental feature of the Earth, namely its topography, is problematic.

74 Theoretically, the physical principles controlling topography were quantified in many fundamental

75 studies (e.g., above references) and, given enough information, topography can be predicted. In

76 practice, however, in most regions of the world all the parameters that are needed for those

77 calculations are not available. So, the practical question becomes whether a set of useful and simple

78 rules that relate topography to lithospheric structure in various tectonic environments can be deduced

79 in a way that missing parameters can be guessed reasonably well; or does each area behave differently.

80 In a previous study (Zoback and Mooney, 2003) that used 1700 crustal structure profiles from the global

81 database compiled by the US Geological Survey (Mooney et al., 2002), crustal contribution to

82 topography was shown to be always much higher than the observed topography. Zoback and Mooney

83 (2003) explained that the negative buoyancy of the ML lowers the observed topography by $1.73 \mathrm{~km}$ on

84 average (Fig. 1). Moreover, they computed the thickness of the ML for each point in their dataset and

85 showed that lithospheric thickness deduced from isostasy generally agrees with seismic data.

86 However, the individual analysis of each data point still does not reduce the scatter covering the crustal

87 thickness-topography diagram (Fig. 1). Can we explain the distribution of points within this cloud? Can

88 we distinguish clusters related to distinct tectonic environments as shown by Hyndman and Currie

89 (2011) for North Western America (hot Cordillera vs. cold craton)? Or is it too complex for any useful

90 global rules? 
91 This study tries to answer these questions emphasizing the phenomenology. For this purpose we chose

92 the Mediterranean - Red Sea domain (Fig. 2) that includes a variety of tectonic environments: inter- and

93 intra-plate regions; active and passive continental margins; and cool versus hot mantle regions. We

94 examine the relationships between tectonic setting and crustal density, strive to remove the

95 contribution of the crust from the observed elevation, and interpret the residual topography in terms of

$96 \mathrm{ML}$ buoyancy, plate bending, and dynamics. Based on the conjunction between the Afar Plume and the

97 mid ocean ridge in the nearby Gulf of Aden and southern Red Sea, we constrain the amplitude of

98 dynamic topography. Based on understanding the lithospheric structure in the Mesopotamian, Ionian,

99 and Herodotus basins we constrain the amplitude of the downward pull force exerted by subduction

100 (flexure and dynamic topography).

101 In addition to the general contribution of this study to the issue of isostasy and topography, the

102 distinction between static and dynamic processes in the Red-Sea/Middle-East/Mediterranean domain is

103 of special interest. In this part of the world dynamics is related to mantle flow from the Afar plume in

104 East Africa, through the Middle East, all the way to Anatolia and the Aegean Sea (Daradich et al., 2003;

105 Forte et al., 2010; Chang, and Van der Lee, 2011; Becker and Faccenna, 2011; Faccenna et al., 2013,

106 2014; Sembroni et al., 2016; Bar et al., 2016). Our analysis constrains the vertical effect of this dynamic

107 flow.

\subsection{Formulation}

110 The mean elevation $\varepsilon$, of a region depends on the local lithospheric buoyancy $H$, dynamic topography $D T$

111 (e.g., upwelling mantle plume), and flexure $F L$. In this formulation $F L$ refers to short wavelength elastic 
112 flexure as well as to long wavelength inelastic bending of foreland and forearc basins caused by far-off

113 subducting slabs.

$114 \varepsilon=a(H+D T+F L)$,

$a=1 \quad \varepsilon \geq 0$

115

$a=\frac{\rho_{a}}{\rho_{a}-\rho_{w}} \quad \varepsilon<0$

116 where $a$ expresses the deepening of ocean floor due to the water load; and $\rho_{a}$ and $\rho_{w}$ are the densities

117 of the asthenosphere and water, respectively.

118 Considering that lithospheric buoyancy $H$, is a sum of contributions from the buoyancies of the crust $\left(H_{c}\right)$

119 and the mantle lithosphere $\left(H_{\mathrm{ml}}\right)$, eq. 1 can be expanded as:

$120 \varepsilon=a\left(H_{\mathrm{c}}+H_{\mathrm{ml}}-\mathrm{H}_{0}+D T+F L\right)$,

121 where $H_{0}$ is a constant that allows using sea level as a reference datum instead of a theoretical free

122 asthenosphere surface. $\mathrm{H}_{0}=2.4 \mathrm{~km}$ makes eq. 1 consistent with density and elevations of mid-oceans

123 ridges (Lachenbruch and Morgan, 1990).

124 The quantities $H_{\mathrm{c}}$ and $H_{\mathrm{ml}}$ are defined as:

$125 \quad H_{\mathrm{c}}=\frac{1}{\rho_{\mathrm{a}}}\left(\rho_{\mathrm{a}}-\rho_{\mathrm{c}}\right) L_{\mathrm{c}}$,

126 and

$127 \quad H_{\mathrm{ml}}=\frac{1}{\rho_{\mathrm{a}}}\left(\rho_{\mathrm{a}}-\rho_{\mathrm{ml}}\right) L_{\mathrm{ml}}$, 
128 where $\rho_{\mathrm{c}}, \rho_{\mathrm{ml}}$ and $L_{\mathrm{c}}, L_{\mathrm{ml}}$ are the mean densities and the thickness of the crust and the mantle

129 lithosphere, respectively.

130 If the lithosphere consists only of crust (e.g., mid ocean ridges), then $L_{\mathrm{ml}}=0$ and the elevation would be:

$131 \varepsilon_{c}=H_{\mathrm{c}}-H_{0}$.

132 In cases of local isostatic equilibrium, here the dynamic and flexural components are negligible,

$133 \varepsilon=a\left(\varepsilon_{\mathrm{c}}+H_{\mathrm{ml}}\right)$,

$134 \quad H_{m l}=\frac{\varepsilon}{a}-\varepsilon_{\mathrm{c}}$

135 and, thus, the thickness of the ML can be calculated:

$136 \quad L_{\mathrm{ml}}=\frac{\rho_{\mathrm{a}}}{\left(\rho_{\mathrm{a}}-\rho_{\mathrm{ml}}\right)}\left(\frac{\varepsilon}{a}+H_{0}-H_{\mathrm{c}}\right)$,

137 Note that for this calculation the ratio $\frac{\rho_{\mathrm{a}}}{\left(\rho_{\mathrm{a}}-\rho_{\mathrm{ml}}\right)}$ is the important factor rather than the absolute densities

138 of the $\mathrm{ML}$ and asthenosphere. This density ratio depends on the temperature difference between the

139 hot asthenosphere and the cool ML (e.g., Parsons and Sclater, 1977):

$140 \rho_{m l}=\rho_{a}\left[1+\alpha\left(\theta_{a}-\theta_{m l}\right)\right]$,

141 Where $\theta_{\mathrm{a}}$ and $\theta_{\mathrm{ml}}$ are the temperatures of the asthenosphere and average $\mathrm{ML}$, respectively, and $\alpha$ is the

142 volume coefficient of thermal expansion. In this study we use $\theta_{a}=1350^{\circ} \mathrm{C}, \alpha=3.5 \cdot 10^{-5}{ }^{0} \mathrm{C}^{-1}$, and

$143 \rho_{\mathrm{a}}=3190 \mathrm{~kg} \cdot \mathrm{m}^{-3}$.

144 Assuming a linear geotherm for the $M L$, the average temperature of the $M L$ is simply

$145 \theta_{m l}=\frac{1}{2}\left(\theta_{c}+\theta_{a}\right)$, 
146 where $\theta_{c}$ is the temperature at the Moho. Supplementary Fig. 1a illustrates that the average

147 temperature, and accordingly density, of the $M L$ is independent of its thickness, but only depends on

148 the temperatures at its boundaries. In practice, thermal models of the crust or lithosphere commonly

149 provide temperature maps at a constant depth (e.g., Artemieva, 2006) and not at the laterally varying

150 Moho level. However, a first order estimation of Moho temperature can be obtained from a simple

151 linear approximation (Supplementary Fig. 1b). The error associated with this approximation is usually

152 smaller than the uncertainty in the temperature data and its influence on density is quite small.

153 For the general case, in which DT and flexure cannot be ignored (in other words isostatic equilibrium is

154 not maintained locally and eqs. 6-8 do not apply), subtraction of crustal buoyancy from the observed

155 topography is termed residual topography, RT:

$156 R T=\frac{\varepsilon}{a}+H_{0}-H_{\mathrm{c}}=H_{m l}+D T+F L$.

157 A main challenge of this study is to identify and constrain $D T$ and $F L$ where they are important and to

158 allow a simple isostatic calculation of $H_{m l}$ and $L_{m l}$ in the rest of the world. For this we, first, show the

159 results of an isostatic approach that interprets RT in terms of $H_{m l}$ and $L_{m l}$ limiting DT only to areas where

160 isostasy alone cannot explain the observations (mantle plumes and subduction zones). Then, we discuss

161 the error in $L_{m l}$ associated with ignoring DT.

\subsection{Research strategy}

163 Currently there is a significant difference between the quality and quantity of information about the 164 crust and the information about the ML. This difference is partly related to the simple fact that the base 165 of the crust is much shallower than the base of the lithosphere; but also to the somewhat vague nature 166 of the lithosphere-asthenosphere boundary (LAB), which is gradual and definition dependent (discussion 167 below). 
168 Since the Moho is better defined than the LAB, we adopt a top-down strategy. We begin with the crust

169 and remove its contribution to the observed topography and only then try to interpret the residual

170 topography. Also, considering that with poor knowledge of Moho depth our exercise is useless, our first

171 effort is to improve the Moho map in the East Africa - Middle East region, where a lot of data not

172 included in previously published datasets are available. We also paid special attention to the gridding

173 method. Since in many cases data points are collected along roads crossing geological structures,

174 automatic gridding wrongly connects data points across geological boundaries. Therefore, when

175 necessary, we forced contours to follow topographic and geological strike lines. Lastly, we generated a

176 grid of $0.5^{\circ}$ spacing, averaging the topography of a few tens of kilometers for each node (later, when we

177 interpret RT we further smooth our results beyond a flexural wavelength of $100-200 \mathrm{~km}$ ).

178 To better understand the relations between residual topography and tectonic environments, we focus

179 on 20 regions: Gulf of Aden, Western Yemen, Afar Rift, Ethiopian Plateau, Anatolia, Pannonian Basin,

180 Carlsberg Ridge, Arabian Sea, Atlantic Ocean, Zagros, Alps, North Africa, Arabia, Levant Basin, Black Sea,

181 Eastern European Platform, South Caspian Sea, Herodotus Basin, Ionian Basin, Mesopotamian Basin, and

182 the Persian Gulf (Fig. 2b). We illustrate that the selected regions reveal a systematic order that is hard to

183 distinguish otherwise.

184 A particular challenge is to interpret the residual topography. In areas of high RT we need to distinguish

185 between a static state of a thin lithosphere and a dynamic state of a lithosphere that is pushed up by an

186 upwelling mantle flow. We use the southern Red Sea-Afar-Aden conjunction for that. In areas of low RT

187 our challenge is to distinguish between the effect of a thick lithosphere and the down-bending of the

188 lithosphere towards subduction. This discussion is illustrated on foreland basins. Lastly, we suggest

189 several typical combinations of topography and lithospheric structures for various tectonic

190 environments. 
192 Topography was taken from ETOPO1 which is a 1 arc-minute global model (Amante and Eakins, 2009;

193 downloaded June 26, 2012). In order to avoid sharp topographic variations that are not compensated

194 locally, we have generated a coarser topographic grid of $0.5^{\circ}$ for buoyancy calculations.

195 As a starting point for the crust, we use CRUST1.0 (http://igppweb.ucsd.edu/ gabi/rem.html, Laske et 196 al., 2013, which is an update of CRUST2.0 (Bassin, et al., 2000) and CRUST5.1 (Mooney, et al., 1998)), a 197 global model of $1^{\circ} \times 1^{\circ}$ resolution with 8 layers, including Moho depth (Fig. 3a), sediment thickness (Fig 198 3b), average sediment density (Fig. 3c), average crystalline crust density (Fig. 3d), and average crustal 199 density (Fig. 3e). For Europe we used the $0.1^{\circ} \times 0.1^{\circ}$ Moho map by Grad et al. (2009) (Fig. 3f).

200 Examining the crystalline crust density map of CRUST1.0 (Fig. 3e), we identify major variations that 201 resemble those of the sediment thickness map (Fig. 3b). We suspect that these variations in the 202 crystalline crust are not derived from measurements, but reflect residuals from sediment distribution.

203 Thus, we prefer using a simplified model including only two types of crystalline crust (oceanic and 204 continental) as shown below.

205 For our new compilation of crustal thickness in the East Africa-Middle East region, we attempted to 206 collect all published data within the area marked in Fig. 4 by a polygon (details in Table 1 supplementary 207 material). We used seismic refraction surveys, receiver function Moho depth estimates, and in some 208 places local Moho maps. We avoided using gravity driven maps which are more interpretation209 dependent and a priori assume isostatic equilibrium. 


\subsection{New Moho map}

212 Differences between our map and previous compilations which result from the new data we used are 213 seen mainly in Anatolia, Iran, East Africa, and Yemen (references in Table 1, Supplementary material).

214 Other significant changes are related to the strategy of interpolation. For example, quite a few data 215 points indicate a relatively thin crust $(\sim 30 \mathrm{~km})$ in the south Caspian Sea a few hundred kilometers

216 offshore. In addition, many other data points along the Alborz Mountain chain indicate a much thicker 217 crust ( $50 \mathrm{~km})$. Automatic gridding yields a gradual transition along a few hundred kilometers, whereas 218 we forced a sharp transition following the collisional plate boundary.

219 Another example is the Red Sea. Three clusters of data points are available in the north, central and 220 southern Red Sea. With the absence of additional data points along most of the Red Sea, automatic 221 gridding will not generate a narrow elongated feature unless contours are forced to a Red Sea parallel

222 trend. This problem increases when the resolution is too low to express changes detected along

223 transects lines. For instance, the Moho map of CRUST1.0 (Fig. 3a) is not resolved enough to express the 224 transition from mountains, to coast, to narrow shelf, and eventually to an oceanic spreading center. In 225 our map, we forced an elongated trend with $\sim 7 \mathrm{~km}$ thick crust along the loci of spreading. Similarly, for 226 the oceanic crust of the Gulf of Aden we used a $7 \mathrm{~km}$ thick crust where no other information exists as 227 also seen in CRUST1.0.

228 Our map includes many other differences compared to previous compilations for example in the 229 Levantine region (Syria, Lebanon, Israel, and Egypt) we distinguish the Lebanese and the Palmyrides 230 mountain chains, which are not recognized in CRUST1.0. Minor changes are also noticed in Israel and 231 Jordan due to many receiver function estimates in that area. 
232 We cannot accurately determine the errors in our new Moho map, because the needed information in

233 the various sources we used is usually not available. Nonetheless, we estimate that the range of

234 uncertainty is 1-2 km for provinces with crustal thicknesses of 5-15 km; 2-3 km for 15-25 km; 3-4 km for $23525-35 \mathrm{~km}$; 4-5 km for 35-45 km; and 5-8 km for a 45-60 km thick crust. A similar range of uncertainty is

236 described by Grad et al. (2009) for Europe (details in Fig. 4). In central Africa (not crucial for our

237 analysis), which was not included in our compilation and where crustal thickness is taken from

238 CRUST1.0, errors may be larger. Implications of crustal thickness uncertainties are discussed below.

\subsection{Crustal density and temperature}

Since we suspect that the density map for the crystalline crust in the CRUST1.0 model includes artifacts

241 resulting from sediment distribution, we prepared a simplified bi-modal distribution map: oceanic

242 crystalline crust with average density of $2950 \mathrm{~kg} / \mathrm{m}^{3}$ and continental crystalline crust with average

243 density of $2840 \mathrm{~kg} / \mathrm{m}^{3}$ (Fig. 5b). Combining this map and the sediment density map of CRUST1.0 we

244 generated the average crustal density map of Fig. 5c, which slightly differs from the crustal density map 245 of CRUST1.0 (Fig. 3e).The Moho temperature map of Fig. $5 \mathrm{~d}$ was derived from a constant $40 \mathrm{~km}$ depth

246 temperature map of Artemieva (2006) corrected for the depth difference between $40 \mathrm{~km}$ and the local

247 Moho. Lastly, the density of the ML was calculated from Moho temperature using eqs. 9-10 (Fig. 5e).

\subsection{Crustal contribution to topography}

249 As expected, the main trend in the map of crustal contribution to topography $H_{c}$ (Fig. 6a), resembles the 250 main trends of the Moho map, but this does not allow identifying the influence of crustal density. To 251 examine how big the density factor is, Fig. 7a plots $H_{c}$ versus crustal thickness $L_{c}$, for 20 selected tectonic 252 regions. Oceanic basins such as the Arabian Sea and Gulf of Aden with their thin sedimentary cover fall 253 along the $2900 \mathrm{~kg} / \mathrm{m}^{3}$ line, consistent with a nearly gabbroic crust. The Zagros, Alps, East Africa, Yemen, 254 and Anatolia, fall between the $2800 \mathrm{~kg} / \mathrm{m}^{3}$ and $2900 \mathrm{~kg} / \mathrm{m}^{3}$, consistent with a nearly granitic crust. 
255 Exceptionally thick sedimentary basins with a relatively thin crystalline crust, such as the Levant, Black

256 Sea, Herodotus, and Ionian Basins, fall above the $2700 \mathrm{~kg} / \mathrm{m}^{3}$ line, which is quite low for the Earth's

257 crust.

258 This is a reminder that common density variations can easily influence Earth's topography by more than

259 a kilometer and cannot be neglected. More encouraging, these variations can be estimated considering

260 the tectonic environment, and specifically, the sedimentary cover and type of crystalline crust. Typical

261 crustal density values are: $2900 \mathrm{~kg} / \mathrm{m}^{3}$ for oceanic basins with a thin sedimentary cover, $2850 \mathrm{~kg} / \mathrm{m}^{3}$ for

262 continental areas with a thick crust and thin sedimentary cover, $2750 \mathrm{~kg} / \mathrm{m}^{3}$ for most sedimentary

263 basins, $2650 \mathrm{~kg} / \mathrm{m}^{3}$ for exceptionally thick sedimentary basins, where the less dense sediments

264 significantly lower the crustal average, and a default common values of $2800 \mathrm{~kg} / \mathrm{m}^{3}$ for all other regions.

265 In other words, the uncertainty in crustal mean density should be in the order of the variance within

266 each cluster of Fig. 7a, that is, $\sim 50 \mathrm{~kg} / \mathrm{m}^{3}$ for most provinces, $\sim 100 \mathrm{~kg} / \mathrm{m}^{3}$ in deep oceanic basins, where

267 uncompacted sediments overly a dense gabbroic crust, and $\sim 25 \mathrm{~kg} / \mathrm{m}^{3}$ in regions of nearly pure

268 continental crust.

269 Considering the range of uncertainty in crustal thickness and density, the uncertainty in $\mathrm{H}_{\mathrm{c}}$ that is

270 directly transferred to RT is in the order of $\pm 100-500 \mathrm{~m}$ for regions with crustal thicknesses of 5-15 km

271 (largest uncertainty in density, but small uncertainty in thickness); 400-700 m for 15-25 km; 700-1000 m

272 for $25-35 \mathrm{~km}$; $1000-1500 \mathrm{~m}$ for $35-45 \mathrm{~km}$ and also for $45-60 \mathrm{~km}$ thick crust (largest uncertainty in

273 thickness, but lesser uncertainty in density).

\subsection{Residual topography}

275 The residual topography map of Fig. $6 \mathrm{~b}$ is dominated by hot colors expressing values between $-1 \mathrm{~km}$ and

$2761 \mathrm{~km}$ and blue colors expressing values lower than $-3 \mathrm{~km}$. However, this situation is clearly abnormal.

277 Empirically, the world average is $-1.73 \mathrm{~km}$ (Zoback and Mooney, 2003) and, theoretically, the calculated 
278 buoyancy of $80-100 \mathrm{~km}$ thick ML is between $-1.0 \mathrm{~km}$ and $-2.0 \mathrm{~km}$ (Fig. 3 of Lachenbruch and Morgan,

279 1990). In other words, only the gray regions in the RT map of Fig. $6 \mathrm{~b}$ are "normal", whereas most of the

280 study area is higher or lower than expected from a stable isostatic lithosphere. The challenge now is to

281 interpret the RT in this unique area and to distinguish between ML buoyancy and dynamic topography

282 due to upwelling or to down-bending of the lithosphere towards subduction.

\subsection{Residual topography and tectonic environments}

284 To better understand the relations between residual topography and tectonic environments, we focus

285 again on the 20 chosen tectonic areas (Fig. 8a). The first prominent observation is that positive RT is

286 observed in Aden, Ethiopia, and SW Yemen, that is, around the upwelling Afar mantle plume. Positive RT

287 cannot be related to the buoyancy of the ML, which must be negative or zero where it does not exist

288 (i.e., mid ocean ridges like the Carlsberg Ridge).

289 The second prominent observation is that exceptionally low RT of $-3 \mathrm{~km}$ to $-5 \mathrm{~km}$ is observed in forearc

290 (Ionian Basin and Herodotus Basin) or foreland basins (Mesopotamian Basin, Persian Gulf, and South

291 Caspian Sea), where the lithosphere bends towards convergence plate boundaries. This bending

292 perturbs the isostatic equilibrium as also indicated by exceptionally low free air gravity anomalies (Fig.

2932 2b). Even in the Herodotus and Ionian Basins that probably have the oldest oceanic crust on Earth

294 (Speranza et al., 2012), the exceptionally low RT is not explained by thermal cooling of the lithosphere,

295 because thermal cooling cannot contribute much more than $2 \mathrm{~km}$ of subsidence (not including water

296 load) (Lachenbruch and Morgan, 1990) and hence the difference between $150 \mathrm{Ma}$ and $250 \mathrm{Ma}$ of

297 cooling is no more than a few hundred meters.

298 Plotting residual topography against crustal thickness (Fig. 8b) shows that crustal thickness distinguishes

299 between very thin (e.g., oceanic), thin (stretched continents), intermediate (common continents), and thickened (orogens) crust; and RT distinguishes between hot and cold regions. Such a diagram is useful 
301 for describing various geological environments and the amplitude of vertical motions transferring

302 regions from one state to another (e.g., rifting, cooling, etc.).

303 Oceanic floor is generated at mid ocean ridges (MOR) with no ML. Then, while moving away from the 304 spreading center and cooling, their ML gradually thickens and its negative buoyancy increases. In terms 305 of RT these basins begin with RT=0 (e.g., the Carlsberg Ridge excluding its northernmost segment), 306 decreasing to RT of about $-1 \mathrm{~km}$ to $-1.5 \mathrm{~km}$ in Young Oceanic Basins (YOB) like the Arabian Sea, and 307 then further decreasing to $-2 \mathrm{~km}$ in Old Oceanic Basins (OOB) like the old Atlantic margins of West 308 Africa. In view of this typical path the Gulf of Aden is exceptional with its positive RT indicating DT.

309 Stretched continental basins (Afar and Pannonian, Levant, and Black Sea) begin their development as 310 Young Rifted Basins (YRB) with a thin ML that subsequently cools, thickens, and increases its negative 311 buoyancy. The young Pannonian Basin is characterized by RT of $\sim-0.7 \mathrm{~km}$. The older basins of the Black 312 Sea and Levant that have already reached a thermal steady state and thus are characterized by RT of $313-2 \mathrm{~km}$ to $-3 \mathrm{~km}$. In view of this typical path the Afar Rift with its positive RT is exceptional indicating 314 dynamic uplift. Another exception is the Ionian and Herodotus Basins (central Mediterranean), which 315 are very deep relative to their crustal thickness with RT ranging from $-3 \mathrm{~km}$ to $-5 \mathrm{~km}$. These forearc 316 basins are clearly subduction related (SRFB, subduction related forearc/foreland basins).

317 Stable Continents (SC) such as North Africa and Arabia with their "normal" $30-40 \mathrm{~km}$ thick crust are with 318 "normal" RT of $-1.5 \mathrm{~km}$ to $-2.5 \mathrm{~km}$, as expected from a mature $\mathrm{ML}$, not very different from old oceanic 319 basins (OOB, Atlantic) and old rifted basins (ORB, Levant Basin and Black Sea). Anatolia and parts of the 320 Ethiopian Plateau also have a normal crust ( $35-45 \mathrm{~km}$ thick), but their RT is higher ( $-1 \mathrm{~km}$ to zero). This 321 can express a Thermally Eroded Continent (TEC) with a thin ML, dynamic uplift, or a combination of the 322 two. However, the positive RT in large parts of the Ethiopian plateau and SW Yemen (e.g. Sembroni et 323 al., 2016) cannot be explained even with complete removal of the ML. These areas are thus named 
324 Dynamically Uplifted Continents (DUC) similar to the nearby dynamically uplifted ocean (DUO, Gulf of 325 Aden).

326 Continental regions with normal crustal thickness and RT lower than $-2.5 \mathrm{~km}$ are the East European

327 craton and the Mesopotamian basin (also part of the South Caspian Sea). Whereas old and cold

328 Continental Cratons (CC) may be explained statically with exceptionally thick ML (e.g., Zoback and

329 Mooney, 2003), the Mesopotamian Basin, is clearly related to long wavelength bending towards the

330 Zagros (SRFB subduction related forearc/foreland basins) as also indicated by the gradual tilting of the

331 crystalline basement.

332 The residual topography of orogens (ORO) with a thickened crust (e.g., Zagros and Alps) varies from

$333-0.5 \mathrm{~km}$ to $-2 \mathrm{~km}$, which is a bit higher than old oceanic basins (OOB), old rifted basins (ORB) and stable

334 continents (SC). The reason for that may be crustal thickening on account of the ML or root

335 delamination (Houseman et al., 1981; Platt and England, 1994; Kay and Kay, 1993).

336 To summarize, 1), a mature ML generates a negative buoyancy producing RT of nearly $-2 \mathrm{~km}$ as

337 observed in old oceanic basins (OOB), old rifted basins (ORB), and stable continents (SC). 2) Positive RT

338 in dynamically uplifted oceans (DUO, Aden) and dynamically uplifted continents (DUC, Ethiopian

339 Plateau) clearly expresses dynamic upwelling (It is still not clear, however, if the ML at these regions is

340 completely absent). 3) High RT of $-1 \mathrm{~km}$ to zero as observed in thermally eroded continents (TEC,

341 Anatolia) probably indicates a thin ML, but dynamic uplift may also be involved. 4) Continental Cratons

342 (CC) are associated with a thick ML and low RT of $\sim-3 \mathrm{~km}$. (5) Exceptionally low RT of less than $-3 \mathrm{~km}$ is

343 observed only in subduction related basins within the forearc or foreland basins and even farther away

344 (SRFB, Ionian, Herodotus, and Mesopotamia). 


\section{DISCUSSION}

\subsection{Interpretation of residual topography}

Topography is a first order signal of Earth's dynamics; however, yet its interpretation is not straightforward as it results from the superposition of different signals. We often refer to isostatic and dynamic signal to separate between the lithosphere's static contribution and the dynamic transient contribution related to mantle convection. Here we investigate a region with different tectonic environments: mantle plume, convergent-collisional margin, subduction zone, spreading ridge, and stable cratonic areas. The goal is to provide a robust estimate of the isostatic and dynamic components. For simplicity we, first, present an endmember isostatic approach that interprets RT in terms of $H_{m l}$ and $L_{m l}$ limiting DT only to areas where isostasy alone cannot explain the observations (mantle plumes and subduction zones). Then, we discuss the error in $L_{m l}$ associated with ignoring DT even when it is relatively small.

In reality, the lithosphere above upwelling plumes is hot, thin, and weak and the lithosphere above down-welling mantle flows is cold, strong, and with no indications for thinning. Accordingly, for regions with high residual topography, which are commonly associated with elevated heat flow and magmatism, we first assume that DT $>0$ (mantle flow is upwards), $\mathrm{H}_{\mathrm{ml}}>-2 \mathrm{~km}$ (ML is thinner than normal), and for topographic loads wider than $\sim 100 \mathrm{~km} \mathrm{FL} \approx 0$ (lithosphere is weak). Second, we suggest to take advantage of the unique conjunction of a mantle plume and a mid ocean ridge in the Gulf of Aden and the southern Red Sea (Fig. 6b). At this location $\mathrm{H}_{\mathrm{ml}}=0$, because the $\mathrm{ML}$ is absent along MOR, and DT is nearly maximal, because western Aden is located very close to the center of the plume (Fig. 9a,b). In other words, RT which is $\sim 1 \mathrm{~km}$ in the southern Red Sea and western Aden, represents the regional maximal dynamic uplift (RT=DT $\max \sim 1 \mathrm{~km}$ ) consistent with dynamic topography prediction from present day global mantle flow (Fig. 6e from Faccenna et al., 2014a) using the SAVANI S-wave model (Auer et al., 2014). 
For foreland and forearc basins, we suggest that the exceptionally low residual topography do not indicate $M L$ thickening, because there is no reason to think that the (e.g., Arabian) ML thickens hundreds of kilometers before reaching the subduction plate boundary (e.g., Mesopotamia-Zagros line) (Fig. 9c). Hence, $\mathrm{H}_{\mathrm{ml}}$ in Mesopotamia is similar to $\mathrm{H}_{\mathrm{ml}}$ in Arabia $(\sim-2 \mathrm{~km})$ and the lateral change from RT of $\sim-2 \mathrm{~km}$ in Arabia to $\sim-3.5 \mathrm{~km}$ in Mesopotamia is probably related to the subduction process as also indicated by the large negative free air anomaly (Fig. 2b). Similarly, in the lonian and Herodotus basins, $\mathrm{RT}$ reaches $-5 \mathrm{~km}$ and in the extreme case of the deep south Mariana trench (western Pacific), which is more than $5 \mathrm{~km}$ deeper than the adjacent abyssal plains, RT reaches a world maximum of $\sim-7 \mathrm{~km}$ (Gvirtzman and Stern, 2004). These extremely low RT values definitely do not indicate thickening of the $M L$ and, therefore, we suggest assuming that $M L$ thickness at those areas is similar to $M L$ thickness of the same plates farther back before reaching the area influenced by subduction.

Considering that in the vicinity of the Afar Plume, very close to Aden - Red Sea spreading centers, there is no ML; and considering that in foreland and forearc basins the thickness of the ML is probably similar to its thickness in the unbent portion of the same plate, we focus the discussion on the ability to approximate ML thickness from RT on other regions (most of the study area). To begin this discussion we now examine the consequences of neglecting DT and presuming isostasy. This actually means that in those areas we assume $H_{m l} \approx R T$ and calculate the thickness of the ML using eq. (8). Results of this first order approximation are shown in the lithospheric thickness map of Fig. $6 \mathrm{~d}$.

This exercise is further clarified by Fig. $7 \mathrm{~b}$ showing the relationships between $\mathrm{ML}$ thickness and ML contribution to topography for various ML densities and various tectonic environments. For instance, young oceanic basins fall on the $1000^{\circ} \mathrm{C}$ Moho temperature and $3220 \mathrm{~kg} / \mathrm{m}^{3} \mathrm{ML}$ density; and old oceanic basins fall near the curve of $100^{\circ} \mathrm{C}$ Moho temperature and $3270 \mathrm{~kg} / \mathrm{m}^{3} \mathrm{ML}$ density. Similarly, the Alps have a lighter ML than stable continents, because its Moho is deep and hot. Also note that the East 
391 European Craton is a cold region but its Moho temperature is not so cold, because it is deep. On the

392 contrary, the Ionian and Herodotus basins have a relatively dense ML because their Moho temperature

393 is relatively shallow and cold. In general, Fig. 7b illustrates that changes in ML density can affect the

394 calculation of the ML thickness by $\sim 50 \mathrm{~km}$ and thus cannot be neglected.

395 In the East European Craton the inferred thickness of the calculated ML is larger than $200 \mathrm{~km}$ and the 396 entire lithospheric thickness reaches $250 \mathrm{~km}$. This analysis assumes a pure thermal control on the ML for 397 the sake of argument. However, the density of the ML may be significantly influenced by petrologic 398 variations in continental lithosphere (e.g., Jordan, 1988; Forte and Perry, 2000; O’Reilly at al., 2001; 399 Zoback and Mooney, 2003; Steinberger, 2016). Particularly highly fractionated mantle roots under 400 cratons may be associated with a positive chemical buoyancy anomaly that offsets the negative thermal 401 buoyancy (e.g., Jordan, 1988; Lee et al., 2005), implying that our calculation underestimates the 402 thickness of the ML under cratons. Also, using a constant value for the density of the asthenosphere 403 becomes problematic underneath thick continental lithosphere (e.g. Poudjom-Djomani et al., 2001).

404 The approach adopted here is to explore the possibility that most of the RT is due to intra-lithospheric 405 buoyancy variations. A different perspective is demonstrated, for example, by Forte et al. (2007), 406 who calculate the expected topography variations resulting from lateral buoyancy differences in the 407 upper $200 \mathrm{~km}$ of the mantle and, then, from buoyancy differences located below $200 \mathrm{~km}$; in both 408 cases global-scale undulations of at least $1 \mathrm{~km}$ are obtained. In other words, modeling of mantle 409 circulation shows that DT in regions far away from mantle plumes and forearc/foreland basins can 410 be larger than $\pm 1 \mathrm{~km}$. Examples for regions that do not coincide with simple, isolated mantle plumes 411 or subduction zones and yet are strongly influenced by dynamic topography are Anatolia (Sengor et 412 al., 2003; Boschi et al., 2010), South Africa (Lithgow-Bertelloni and Silver, 1998; Gurnis et al. 2000), 413 Basin and Range (Hyndman and Currie, 2011; Lowry et al., 2000; Becker et al., 2014), and others. 
414 These cases indicate that presuming isostasy even far away from mantle plumes and subduction

415 zones is associated with an error and the question addressed now is how large this error is in the

416 area studied here. For example, in the southern parts of Israel and Jordan RT ranges between -0.6 and

$417-0.7 \mathrm{~km}$ (Fig. 6b) whereas in the adjacent area of central Arabia RT varies between a "normal" value of

$418-2 \mathrm{~km}$ (this study) and a world average value of $-1.7 \mathrm{~km}$ (Zoback and Mooney, 2003). The explanation

419 for the 1.0-1.4 km anomaly in southern Israel and Jordan is most probably a combination of lithospheric

420 thinning and dynamic support, yet what is the relative contribution of these two effects? Considering

421 that the maximal value of DT just above the Afar Plume is only $1 \mathrm{~km}$ and that the Israel-Jordan area is

422 located $2000 \mathrm{~km}$ away, the dynamic effect might decrease to a few hundred meters (100-300 m).

423 Theoretically, the presence of an additional plume beneath Arabia (e.g., Daradich et al., 2003; Chang and

424 Van der Lee, 2011) may increase the dynamic effect in Israel and Jordan. However, using $\mathrm{H}_{\mathrm{ml}}=\mathrm{RT}$ and

425 calculating ML thickness from eq. (8), the total lithospheric thickness in the Jordan-Israel is $70-80 \mathrm{~km}$

426 (Fig. 6d), quite similar to receiver function measurements indicating 60-80 km (Moshen et al., 2006).

427 Apparently, this supports the conclusion that DT in north Arabia is relatively small, because for such an

428 area $10-20 \mathrm{~km}$ in lithospheric thickness corresponds to 100-300 m in RT (Fig. 7b). Nonetheless,

429 considering the widespread trace of volcanism (e.g. Coleman 1993) dynamic contribution cannot be

430 excluded even in north Arabia (Daradich et al. 2003; Becker and Faccenna, 2011; Faccenna et al., 2013).

433 We now return to the large scattering in the topography-crustal thickness diagram (Fig. 1) where the 434 same crustal thickness is commonly accompanied by topographic variations of a few $\mathrm{km}$. Our analysis 435 shows that this scatter depends on the tectonic environment (Fig. 10a). Thus, considering this dependency together with available knowledge about crustal density and Moho temperature, we can 
437 identify regions where isostasy provides a fairly good approximation for the earth's topography and

438 regions where isostasy does not work (Fig. 10b). We envisage that at those regions were isostasy works

439 well, theoretically, topography can be predicted from lithospheric buoyancy given independent

440 measurements of lithospheric thickness (e.g., receiver function measurements or surface waves LAB).

441 Noteworthy, such measurements should be considered with caution because it is not always clear what

442 is exactly measured (e.g. Fischer et al., 2010) and because the LAB is a gradual transition zone with

443 several definitions (cf. Becker et al., 2014). Here, we compute the base of what we define as the isostatic

444 lithosphere, which is similar to the buoyancy determined LAB (e.g., Gvirtzman and Nur, 1999, 2001;

445 Zoback and Mooney, 2003). Isostatic lithosphere does not necessarily coincide with mechanical

446 lithosphere (strong), thermal lithosphere (conductive), or seismic lithosphere (above the low velocity

447 zone).

448 A useful way to generalize our results is to plot them along a schematic plate-tectonic section (Fig. 11d)

449 including variety of tectonic environments and to accompany this section with profiles of all relevant

450 parameters (crustal density, ML density, topography, $\mathrm{H}_{c}$, and RT). This presentation illustrates several

451 rules of thumb in a self-consistent manner. Crustal density varies by $300 \mathrm{~kg} / \mathrm{m}^{3}$ between $2650 \mathrm{~kg} / \mathrm{m}^{3}$ in

452 sedimentary rich basins to $2950 \mathrm{~kg} / \mathrm{m}^{3}$ in oceanic basins (Fig. 11a). Disregarding possible compositional

453 effects, changes in ML density are an order of magnitude lower, changing from $3220 \mathrm{~kg} / \mathrm{m}^{3}$ in hot Moho

454 to $3270 \mathrm{~kg} / \mathrm{m}^{3}$ in cold Moho with low peaks (hot mantle) near oceanic ridges, mantle plumes, and

455 orogens (deep Moho) and high peaks in stretched continental basins and old oceans (shallow Moho)

456 (Fig. 11b). Crustal contribution to topography (Fig. 11c, brown curve) is always higher than the actual

457 topography (black). Residual topography is commonly around $-2 \mathrm{~km}$ with low peaks in foreland basin

458 and cratons and high peaks above upwelling plumes. Topographic highs are controlled by crustal

459 thinning (extended basins), crustal thickening (orogen), thermal erosion (continental plateau), ML 
460 thickening (craton), flexure towards subduction zones (foreland basin), and dynamic support (continents

461 and oceans).

462 Despite this analysis interpretation of RT in many places remain ambiguous. For instance, in Anatolia 463 and in Ethiopia the distinction between ML thinning and dynamic topography (Fig. 8b) is not clear

464 (Sengor et al., 2003; Boschi et al., 2010). These two signals of topography actually express the same 465 phenomena of mantle upwelling that thermally thins the lithosphere and pushed it upwards (e.g., 466 Becker and Faccenna, 2011; Faccenna et al., 2013, 2014a). The question discussed here is not the origin 467 of these processes, but whether or not isostasy correctly accounts for thermal thinning of the 468 lithosphere as it accounts for mechanical thinning of the lithosphere in extended sedimentary basins.

469 Possible solution to this question may arise from quantitative examination of the history of vertical 470 motions (paleotopography), but this is beyond the scope of this study.

471 Moving from uplifted continents to large oceanic basins, the uncertainty in DT may be reduced even far

472 away from mantle plumes, by comparing depth anomalies to age-dependent subsidence curves

473 (Winterbourne et al., 2009; Crosby et al., 2006; Crosby and McKenzie, 2009). In addition, past

474 fluctuations in DT may be reconstructed from stratigraphic evidence of major marine transgressions and 475 regressions (e.g., Mitrovica et al., 1989; Gurnis, 1990a, 1990b; 1993; Bertelloni and Gurnis, 1997;

476 Moucha, et al., 2008; Müller, et al., 2008; Sembroni et al., 2016), though here again, the distinction 477 between lithospheric thinning and DT is not always clear.

479 The difficulty to predict topography from lithospheric structure or, alternatively, estimate lithospheric 480 thickness from residual topography, results from two basic limitations. 1) Factors controlling lithospheric 481 buoyancy in most parts of the world are uncertain; and, 2), non-isostatic factors such as lithospheric 
482 bending and dynamic topography are hard to quantify. In this study we suggest several steps to

483 overcome these difficulties.

484 We examine systematic relationships between tectonic environments and factors controlling

485 topography that supports our understanding and encourage useful approximations. Considering that

486 crustal thickness is a primary condition to our exercise we re-examined all available data to compile a

487 new Moho map for the area of the Red Sea / Middle East / Eastern Mediterranean. We suggest that

488 crustal density can be approximated from its thickness (Moho maps are constantly improving), its origin

489 (oceanic/continental), and its sedimentary cover (thickness and density data available from the oil

490 industry). This approximation allows better calculation of the contribution of the crust to topography,

491 and consequently, the residual topography.

492 We suggest that ML density can be approximated, to first order, from geothermal data and Moho depth.

493 In isostatically supported regions this approximation allows interpreting residual topography in terms of

494 lithospheric thickness.

495 We constrain the amplitude of positive dynamic topography above the Afar plumes to be of 1 km,

496 representing a regional maximum in agreement with other studies (Sembroni et al., 2016). Within the

497 study area, including in northern Arabia, DT is relatively small and neglecting it is associated with an

498 error of only $10-30 \mathrm{~km}$ in lithospheric thickness. This conclusion is supported by receiver function

499 measurements of the LAB in southern Israel and Jordan.

500 We show that in foreland and forearc basins, where the lithosphere bends down, residual topography is

501 extremely low $(-2.5 \mathrm{~km}$ to $-6 \mathrm{~km})$. We argue that since down-going plates do not thicken before

502 entering subduction, the extremely low residual topography in forearc/foreland basins express the slab

503 pull-down force rather than lithospheric thickening. Taking lithospheric thickness under foreland/forearc 
504 basins from adjacent areas, the amplitude of two subduction-related effects (semi-static slab load and

505 dynamic topography) is constrained. Distinction between these two effects is yet problematic.

506 Lastly, we present a simplified plate-tectonic section including variety of tectonic environments with

507 typical profiles of crustal density, ML density, topography, crustal buoyancy, and residual topography.

508 This illustrates how isostasy works and where isostasy alone cannot explain the observations.

\section{ACKNOWLEDGEMENTS}

510 This research was supported by a binational grant from the Ministry of Science \& Technology (Israel) and

511 the Ministry of Foreign Affairs (Italy). Claudio Faccenna was also supported by the ITN Topomod and

512 PRIN projects. Thorsten W. Becker was partially supported by NSF EAR-1250214 and EAR-1338329. We

513 are particularly grateful to Alessandro Forte and other two anonymous reviewers whose comments

514 greatly improved our manuscript.

\section{FIGURE CAPTIONS}

516 Figure 1: Topography versus crustal thickness. a) Original thickness grid points from the global CRUST1.0

517 model vs. median ETOPO1 topography, registered on the same $1 \times 1$ degree grid. Note that many

518 negative topography (oceanic) values are based on an isostatic model within CRUST1.0, rather than

519 data. b) Smoothed representation of CRUST1.0 when thickness is sampled by even area distributed

520 points and crustal thickness is normalized by model density variations (effective thickness $=L_{c} \rho_{c} / \overline{\rho_{c}}$ ).

521 Gray shading indicates density of points within the axes domain represented by a log color scale

522 proportional to relative area (arbitrary units). Blue line is topography predicted from crustal buoyancy.

523 Dashed blue line is the same with a $-1.1 \mathrm{~km}$ shift corresponding to negative buoyancy of a $100 \mathrm{~km}$ thick

$524 \mathrm{ML}$ assuming a density factor of -0.01 . Red line is the same as the blue with a $-1.74 \mathrm{~km}$ shift taken from

525 Zoback and Mooney (2003). Note that many continental areas have a typical crustal thickness of $35 \mathrm{~km}$, 
526 but a large range of elevations. This indicates large deviations from isostasy, whereas the trend of the

527 more extreme values validates the general concept.

528 Figure 2: Location map with (a) topography from ETOPO1 (Amante and Eakins, 2009) and (b) Free Air

529 Gravity from Sandwell and Smith (2009). Black dots are locations within 20 selected tectonic

530 environments that were specifically analyzed. Straight line marks the track of Section 2 (Fig. 9).

531 Figure 3: Crustal datasets. (a) Moho depth. (b) Sediment thickness. (c) Average sediment density. (d)

532 Average density of crystalline crust. (e) Average density of entire crust. (f) Moho depth for Europe. (a-e)

533 taken from CRUST1.0 model (http://igppweb.ucsd.edu/ gabi/rem.html, Laske et al., 2013) and (f) from

534 Grad et al. (2009).

535 Figure 4: Revised Moho map in the East Africa/Middle East region. (a) Moho map generated from

536 CRUST1.0 (Laske et al., 2013) and Grad et al. (2009). (b) The new compilation of this study (marked by a

537 polygon) embedded in previous models. Data points marked by black crosses are taken from seismic

538 refraction lines, blue circles mark receiver function measurements, and magenta circles are points

539 digitized from published Moho maps. Straight line marks the track of Section 2 (Fig. 9).

540 Figure 5: Crustal data used in this study. (a) Moho depth, (b) simplified crystalline crust density: $2.84 \mathrm{~cm}^{3}$

541 for continental crust and $2950 \mathrm{~kg} / \mathrm{m}^{3}$ for oceanic crust, (c) average crustal density, (d) Moho

542 temperature, (e) Average mantle lithosphere density.

543 Figure 6: (a) Crustal contribution to topography, $\mathrm{H}_{\mathrm{c} .}$ (b) Residual topography RT. Dark blue and purple

544 areas represent foreland and forearc basins (south Caspian, NE black sea, Mesopotamia, Herodotus, and

545 Ionian Basins), where RT is exceptionally low $(<-3 \mathrm{~km})$ coinciding with large negative free air anomalies

546 (Fig. 2b). (c) ML thickness, $L_{m l}$, computed from residual topography. In foreland and forearc basins the

547 calculated thickness of the $\mathrm{ML}$ is unrealistically thick (>200 km). White area (positive RT) represents 
548 approximated zone with no ML. (d) Total lithospheric thickness inferred from residual topography. In

549 forearc and foreland basins lithospheric thickness is taken from adjacent areas. In areas with no ML

550 lithospheric thickness equals crustal thickness. (e) Dynamic topography prediction from present day

551 mantle flow (from Faccenna et al., 2014) using the SAVANI S-wave model (Auer et al., 2014). The

552 computation infers topography from instantaneous flow and uses a simple, only radially variable

553 viscosity structure which allows spectral solution via a code such as HC [Milner et al., 2009]. All density

554 anomalies above $100 \mathrm{~km}$ depth are set to zero, and below Vs anomalies are scales as $d \ln \rho / \mathrm{d} \ln \mathrm{Vs}=$

555 0.2, for simplicity. Computation is the same as in Faccenna et al., (2014) (their Figure 14b), see there for

556 detail. Noteworthy, this model shows similar trends as RT (b).

557 Figure 7: Computed contributions of crust and ML to topography for selected tectonic environments. (a)

558 Crustal contributions to topography as a function of crustal thickness and density, (b) ML contribution as

559 a function of ML thickness and density. Note that ML thickness computed from residual topography

560 reaches unrealistically thickness in forearc/foreland basins (see text).

561 Figure 8: Residual topography, tectonic environments, and processes controlling vertical motions. (a)

562 Dependency relationships between residual topography and tectonic settings. (b) Residual topography

563 of the same tectonic provinces as a function of crustal thickness. DUC- dynamically uplifted continent,

564 DUO- dynamically uplifted ocean, MOR- mid ocean ridge, YOB- young ocean basin, OOB old ocean basin,

565 YRB- young rifted basin, ORB- old rifted basin, SRFB- subduction related foreland/forearc basin, TEC-

566 thermally eroded continent, SC- stable continent, CC- cratonic continent, ORO, orogens.

567 Fig 9: Interpretation of residual topography illustrated on a cross section from East Africa to the Caspian

568 Sea (location on Figures 1, 4). (a) Upper panel: measured, smoothed, and residual topography. Lower

569 panel: crust and interpreted LAB. (b) Enlargement of the dynamically uplifted area, where the Afar

570 mantle plume ( $\max$ DT) coincides with the southern Red Sea spreading center $\left(\mathrm{H}_{\mathrm{ml}}=0\right)$. In this area 
571 residual topography constrains the maximal dynamic uplift to $1 \mathrm{~km}$. For inferring the LAB we

572 practically assume RT=DT where RT>0 ( $L A B$ marked red) and $\mathrm{RT}=\mathrm{H}_{\mathrm{ml}}$ for all the rest (blue). The error

573 associated with such approximation is illustrated by a black arrow. (c) Enlargement of the

574 Mesopotamian-Zagros and Caspian-Alborz foreland basins. Assuming that the mantle lithosphere does

575 not thicken under foreland basins, the exceptionally low residual topography is interpreted as the

576 downward-pulled subduction-related force exerted by far-off slab hanging below the orogen.

577 Figure 10: (a) Elevation versus crustal thickness for all grid points in the study area (all black points) and 578 particularly in the selected tectonic provinces (colored points; location in Fig. 2). Compared with the 579 poor correlation between elevation and crustal thickness in Fig. 1, here we show that scattering is

580 systematic and depends on the tectonic settings. (b) Expected correlation between observed and

581 isostatically-calculated topography for different tectonic environments. Whereas, for most

582 environments (black) the expected error is in the order of a few hundred meters, in dynamically uplifted

583 environments (red) and downward pulled subduction-related forearc and foreland basins (blue)

584 deviation from isostasy may reach a few $\mathrm{km}$. (c) 3D illustration of Earth's topography as a function of

585 crustal and mantle lithosphere contributions to lithospheric buoyancy in isostatically balanced areas

586 (less curved surface) and in dynamically affected zones (deflected surface). Subduction related pull

587 down-areas affect cold regions with thick lithosphere (right hand side of the figure). Dynamically uplifted

588 areas affect hot areas with a thin lithosphere (left hand side). Note the difference between thermally

589 eroded continents (TEC), where elevated topography results from lithospheric thinning and dynamically

590 uplifted continents (DUC), where elevated topography is controlled by mantle upwelling. Abbreviations

591 as in Fig. 8. 
593 Figure 11: A simplified plate-tectonic section including variety of tectonic environments with typical

594 profiles of crustal density, ML density, topography, crustal buoyancy, and residual topography, and 595 areas of dynamic uplift and downward pull-down. This illustrates how isostasy works and where isostasy

596 alone cannot explain the observations. Lithospheric thickness in cratons may be larger due to density

597 variations related to petrologic variations, which are not considered in this study.

598

599

600

601

602

603

604

605

606

607

\section{REFERENCES}

609 Airy, G.B., 1855. On the computation of the effect of the attraction of mountain-masses, as

610 disturbing the apparent astronomical latitude of stations in geodetic surveys. Philosophical

611 Transactions of the Royal Society of London, 101-104.

612 Amante, C., Eakins, B.W., 2009. ETOPO1 1 Arc-Minute Global Relief Model: Procedures, Data Sources

613 and Analysis NOAA Technical Memorandum NESDIS NGDC-24, p. 19 
614

615

616

617

618

619

620

621

622

623

624

625

626

627

628

629

630

631

632

633

634

635

636

637

Artemieva, I.M., 2006. Global $1 \times 1$ thermal model TC1 for the continental lithosphere: implications for lithosphere secular evolution. Tectonophysics 416, 245-277.

Auer, L., Boschi, L., Becker, T., Nissen-Meyer, T., Giardini, D., 2014. Savani: A variable resolution whole-mantle model of anisotropic shear velocity variations based on multiple data sets. Journal of Geophysical Research: Solid Earth 119, 3006-3034.

Bar, O., Zilberman, E., Feinstein, S., Calvo, R., Gvirtzman, Z., 2016. The uplift history of the Arabian plateau as inferred from geomorphologic analysis of its northwestern edge, Tectonophysics, 671, 9-23; DOI: 10.1016/j.tecto.2016.01.004.

Bassin, C., Laske, G., Masters, G., 2000. The Current Limits of Resolution for Surface Wave Tomography in North America, EOS Trans AGU, p. F897.

Becker, T.W., Faccenna, C., 2011. Mantle conveyor beneath the Tethyan collisional belt. Earth and Planetary Science Letters 310, 453-461.

Becker, T.W., Faccenna, C., Humphreys, E.D., Lowry, A.R., Miller, M.S., 2014. Static and dynamic support of western United States topography. Earth and Planetary Science Letters 402, 234-246.

Bertelloni, C.L., Gurnis, M., 1997. Cenozoic subsidence and uplift of continents from time-varying dynamic topography. Geology 25, 735-738.

Boschi, L., Faccenna, C., Becker, T., 2010. Mantle structure and dynamic topography in the Mediterranean Basin. Geophysical Research Letters 37.

Cazenave, A., Souriau, A., Dominh, K., 1989. Global coupling of Earth surface topography with hotspots, geoid and mantle heterogeneities. Nature 340, 54-57.

Chang, S.-J., Van der Lee, S., 2011. Mantle plumes and associated flow beneath Arabia and East Africa. Earth and Planetary Science Letters 302, 448-454.

Christensen, U.R., 1998. Dynamic phase boundary topography by latent heat effects. Earth and Planetary Science Letters 154, 295-306. 
Coleman, R., 1993. Geologic evolution of the Red Sea Oxford Monographs on Geology and Geophysics. Oxford University Press, Oxford.

Colin, P., Fleitout, L., 1990. Topography of the ocean floor: Thermal evolution of the lithosphere and interaction of deep mantle heterogeneities with the lithosphere. Geophysical Research Letters 17, 1961-1964.

Crosby, A., McKenzie, D., 2009. An analysis of young ocean depth, gravity and global residual topography. Geophysical Journal International 178, 1198-1219.

Crosby, A., McKenzie, D., Sclater, J., 2006. The relationship between depth, age and gravity in the oceans. Geophysical Journal International 166, 553-573.

Daradich, A., Mitrovica, J.X., Pysklywec, R.N., Willett, S.D., Forte, A.M., 2003. Mantle flow, dynamic topography, and rift-flank uplift of Arabia. Geology 31, 901-904.

Davies, G.F., 1979. Thickness and thermal history of continental crust and root zones. Earth and Planetary Science Letters 44, 231-238.

Dutton, C., 1882. Physics of the Earth's crust; by the Rev. Osmond Fisher., Amer. J. Science 23, 283290.

Faccenna, C., Becker, T.W., Auer, L., Billi, A., Boschi, L., Brun, J.P., Capitanio, F.A., Funiciello, F., Horvàth, F., Jolivet, L., 2014a. Mantle dynamics in the Mediterranean. Reviews of Geophysics. doi: $10.1002 / 2013 R G 000444$.

Faccenna, C., Becker, T.W., Miller, M.S., Serpelloni, E. and Willett, S.D., 2014b. Isostasy, dynamic topography, and the elevation of the Apennines of Italy. Earth and Planetary Science Letters, 407, pp.163-174.

Faccenna, C., and Becker, T.W., 2010. Shaping mobile belt from small scale convection, Nature, Vol 465, doi:10.1038/nature09064. 
Faccenna, C., Becker, T.W., Jolivet, L., Keskin, M., 2013. Mantle convection in the Middle East: Reconciling Afar upwelling, Arabia indentation and Aegean trench rollback. Earth and Planetary Science Letters 375, 254-269.

Fischer, K.M., Ford, H.A., Abt, D.L., Rychert, C.A., 2010. The lithosphere-asthenosphere boundary. Annual Review of Earth and Planetary Sciences 38, 551-575.

Flament, N., Gurnis, M., Müller, R.D., 2013. A review of observations and models of dynamic topography. Lithosphere 5, 189-210.

Forte, A., Peltier, W., Dziewonski, A., Woodward, R., 1993. Dynamic surface topography: a new interpretation based upon mantle flow models derived from seismic tomography. Geophysical Research Letters 20, 225-228.

Forte, A.M., 2007. 1.23 - Constraints on Seismic Models from Other Disciplines - Implications for Mantle Dynamics and Composition, in: Schubert, G. (Ed.), Treatise on Geophysics. Elsevier, Amsterdam, pp. 805-858.

Forte, A.M., Perry, H.C., 2000. Geodynamic evidence for a chemically depleted continental tectosphere. Science 290, 1940-1944.

Forte, A.M., Quéré, S., Moucha, R., Simmons, N.A., Grand, S.P., Mitrovica, J.X., Rowley, D.B., 2010. Joint seismic-geodynamic-mineral physical modelling of African geodynamics: A reconciliation of deep-mantle convection with surface geophysical constraints. Earth and Planetary Science Letters 295, 329-341.

Grad, M., Tiira, T., 2009. The Moho depth map of the European Plate. Geophysical Journal International 176, 279-292.

Gurnis, M., 1990. Bounds on global dynamic topography from Phanerozoic flooding of continental platforms. Nature 344, 754-756.

Gurnis, M., 1990. Ridge spreading, subduction, and sea level fluctuations. Science 250, 970-972. 
Gurnis, M., 1993. Comment on “Dynamic surface topography: A new interpretation based upon mantle flow models derived from seismic tomography" by AM Forte, WR Peltier, AM Dziewonski and RL Woodward. Geophysical Research Letters 20, 1663-1664.

Gurnis, M., 1993. Phanerozoic Marine Inundation of Continents Driven by Dynamic Topography above Subducting Slabs. Nature 364, 589-593.

Gurnis, M., Mitrovica, J.X., Ritsema, J., van Heijst, H.J., 2000. Constraining mantle density structure using geological evidence of surface uplift rates: The case of the African superplume. Geochemistry, Geophysics, Geosystems 1.

Gurnis, M., Müller, R.D., Moresi, L., 1998. Cretaceous vertical motion of Australia and the AustralianAntarctic discordance. Science 279, 1499-1504.

Gvirtzman, Z., Nur, A., 1999. Plate detachment, asthenosphere upwelling, and topography across subduction zones. Geology 27, 563-566.

Gvirtzman, Z., Nur, A., 2001. Residual topography, lithospheric structure and sunken slabs in the central Mediterranean. Earth and Planetary Science Letters 187, 117-130.

Gvirtzman, Z., Stern, R.J., 2004. Bathymetry of Mariana trench-arc system and formation of the Challenger Deep as a consequence of weak plate coupling. Tectonics 23.

Hager, B.H., Clayton, R.W., Richards, M.A., Comer, R.P., Dziewonski, A.M., 1985. Lower mantle heterogeneity, dynamic topography and the geoid. Nature 313, 541-545.

Haxby, W.F., Turcotte, D.L., 1978. On isostatic geoid anomalies. Journal of Geophysical Research: Solid Earth 83, 5473-5478.

Heiskanen, W., Vening Meinesz, FA, 1958. The Earth and Its Gravity Field. McGraw, NY. Houseman, G.A., McKenzie, D.P., Molnar, P., 1981. Convective instability of a thickened boundary layer and its relevance for the thermal evolution of continental convergent belts. Journal of Geophysical Research 86, 6115-6132. 
Hyndman, R., Currie, C., 2011. Why is the North America Cordillera high? Hot backarcs, thermal isostasy, and mountain belts. Geology 39, 783-786.

Kay, R.W., Mahlburg Kay, S., 1993. Delamination and delamination magmatism. Tectonophysics 219, 177-189.

Lachenbruch, A.H., Morgan, P., 1990. Continental extension, magmatism and elevation; formal relations and rules of thumb. Tectonophysics $174,39-62$.

Laske, G., Masters, G., Ma, Z., Pasyanos, M., 2013. Update on CRUST1. 0-A 1-degree Global Model of Earth's Crust, EGU General Assembly Conference Abstracts, p. 2658.

Le Stunff, Y., Ricard, Y., 1995. Topography and geoid due to lithospheric mass anomalies. Geophysical Journal International 122, 982-990.

Lee, C.-T.A., Lenardic, A., Cooper, C.M., Niu, F., Levander, A., 2005. The role of chemical boundary layers in regulating the thickness of continental and oceanic thermal boundary layers. Earth and Planetary Science Letters 230, 379-395.

Lithgow-Bertelloni, C., Silver, P.G., 1998. Dynamic topography, plate driving forces and the African superswell. Nature 395, 269-272.

Lowry, A.R., Ribe, N.M., Smith, R.B., 2000. Dynamic elevation of the Cordillera, western United States. Journal of Geophysical Research: Solid Earth (1978-2012) 105, 23371-23390.

Milner, K., T. W. Becker, L. Boschi, J. Sain, D. Schorlemmer, and H. Waterhouse (2009), The Solid Earth Research and Teaching Environment: A new software framework to share research tools in the classroom and across disciplines, Eos Trans. AGU, 90, 12, doi:10.1029/2009E0120005. Mitrovica, J., Beaumont, C., Jarvis, G., 1989. Tilting of continental interiors by the dynamical effects of subduction. Tectonics 8, 1079-1094.

Mohsen, A., Kind, R., Sobolev, S.V., Weber, M., 2006. Thickness of the lithosphere east of the Dead Sea Transform. Geophysical Journal International 167, 845-852. 
Mooney, W.D., Laske, G., Masters, T.G., 1998. CRUST 5.1: A global crustal model at $5 \times 5$. Journal of Geophysical Research: Solid Earth (1978-2012) 103, 727-747.

Mooney, W.D., Prodehl, C., Pavlenkova, N., 2002. Seismic velocity structure of the continental lithosphere from controlled source data. INTERNATIONAL GEOPHYSICS SERIES 81, 887-910.

Moucha, R., Forte, A.M., 2011. Changes in African topography driven by mantle convection. Nature Geosci 4, 707-712.

Moucha, R., Forte, A.M., Mitrovica, J.X., Rowley, D.B., Quere, S., Simmons, N.A., Grand, S.P., 2008. Dynamic topography and long-term sea-level variations: There is no such thing as a stable continental platform. Earth and Planetary Science Letters 271, 101-108.

Müller, R.D., Sdrolias, M., Gaina, C., Steinberger, B., Heine, C., 2008. Long-term sea-level fluctuations driven by ocean basin dynamics. Science 319, 1357-1362.

O'Reilly, S., Griffin, W., Poudjom Djomani, Y., Morgan, P., 2001. Are lithospheres forever. Tracking changes in subcontinental lithospheric mantle through time: GSA Today 11, 4-10.

Panasyuk, S.V., Hager, B.H., 2000. Inversion for mantle viscosity profiles constrained by dynamic topography and the geoid, and their estimated errors. Geophysical Journal International 143, 821-836.

Parsons, B., Sclater, J.G., 1977. An analysis of the variation of ocean floor bathymetry and heat flow with age. J. geophys. Res 82, 803-827.

Platt, J., England, P., 1994. Convective removal of lithosphere beneath mountain belts; thermal and mechanical consequences. American Journal of Science 294, 307-336.

Djomani, Y.H.P., O’Reilly, S.Y., Griffin, W.L. and Morgan, P., 2001. The density structure of subcontinental lithosphere through time. Earth and Planetary Science Letters, 184(3), pp.605621.

Royden, L.H., 1993. The tectonic expression slab pull at continental convergent boundaries. Tectonics $12,303-325$. 
Sandwell, D.T., Smith, W.H., 2009. Global marine gravity from retracked Geosat and ERS-1 altimetry: Ridge segmentation versus spreading rate. Journal of Geophysical Research: Solid Earth (19782012) 114.

Şengör, A., Özeren, S., Genç, T., Zor, E., 2003. East Anatolian high plateau as a mantle-supported, north-south shortened domal structure. Geophysical Research Letters 30.

Sembroni, A., C. Faccenna, T. W. Becker, P. Molin, and B. Abebe (2016), Longterm, deep-mantle support of the Ethiopia-Yemen Plateau, Tectonics, 35, 469-488, doi:10.1002/2015TC004000

Speranza, F., Minelli, L., Pignatelli, A., Chiappini, M., 2012. The lonian Sea: The oldest in situ ocean fragment of the world? Journal of Geophysical Research: Solid Earth (1978-2012) 117.

Steinberger, B., 2016. Topography caused by mantle density variations: observation-based estimates and models derived from tomography and lithosphere thickness

Thompson, G.A., Talwani, M., 1964. Geology of the crust and mantle, Western United States. Science $146,1539-1549$.

Thoraval, C., Machetel, P., Cazenave, A., 1995. Locally layered convection inferred from dynamic models of the Earth's mantle.

Watts, A.B., 2001. Isostasy and Flexure of the Lithosphere. Cambridge University Press.

Winterbourne, J., Crosby, A., White, N., 2009. Depth, age and dynamic topography of oceanic lithosphere beneath heavily sedimented Atlantic margins. Earth and Planetary Science Letters $287,137-151$.

Zoback, M.L., Mooney, W.D., 2003. Lithospheric buoyancy and continental intraplate stresses. International Geology Review 45, 95-118. 

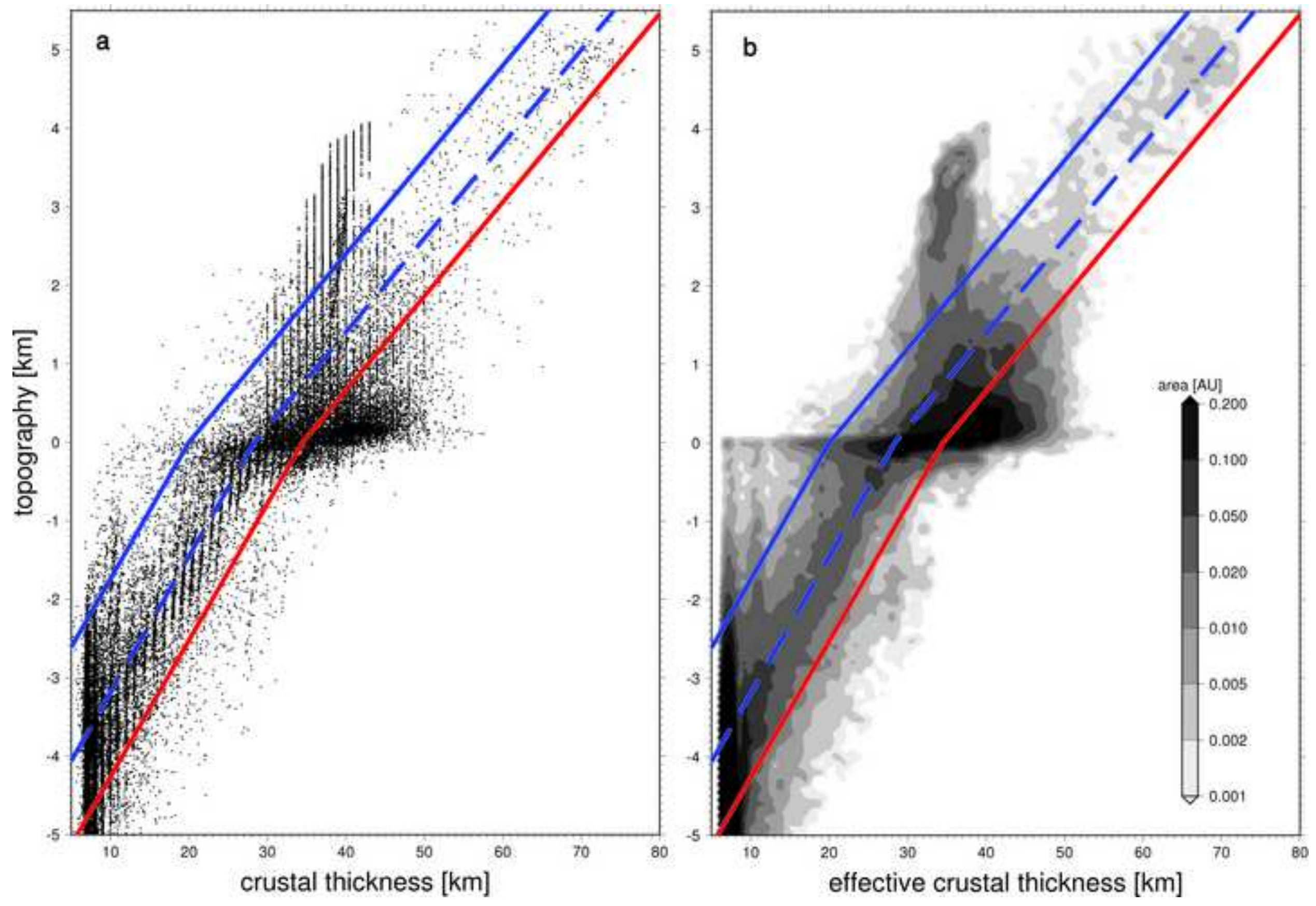
Figure2
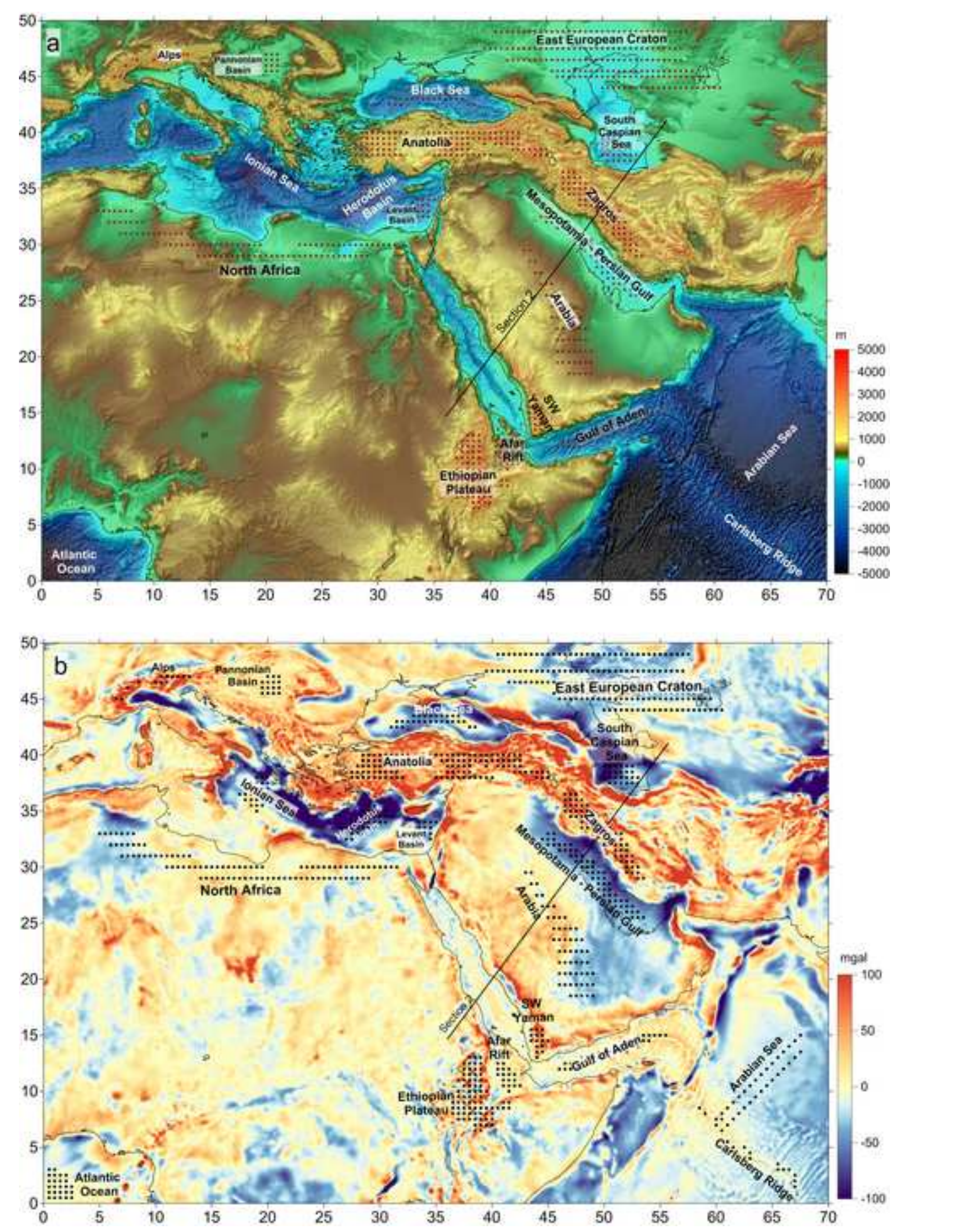

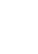

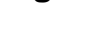

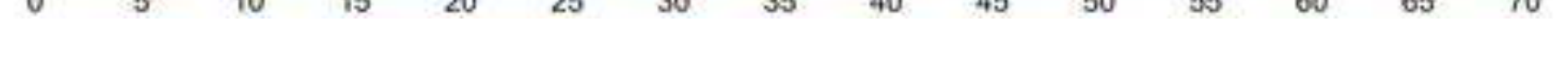



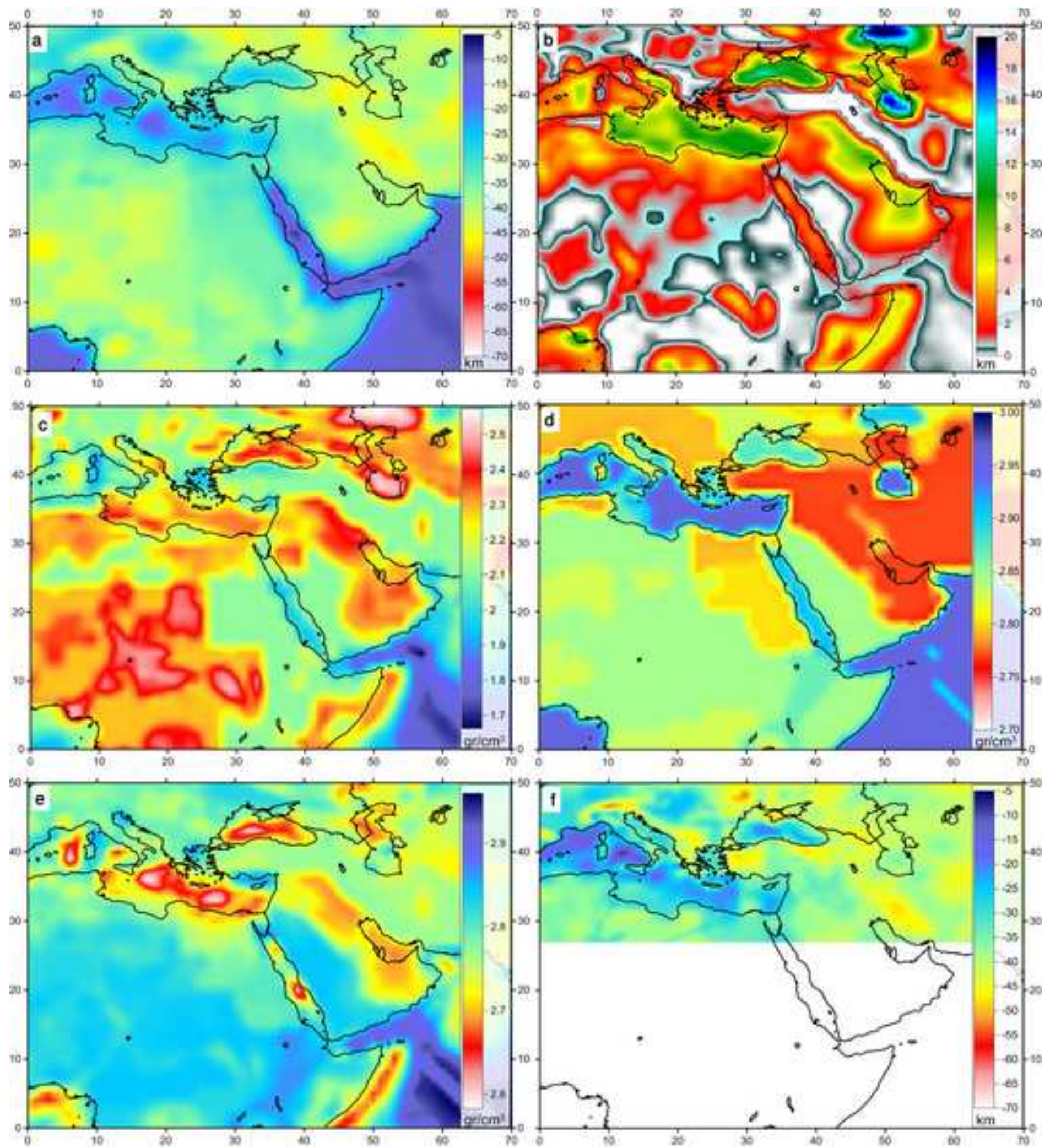

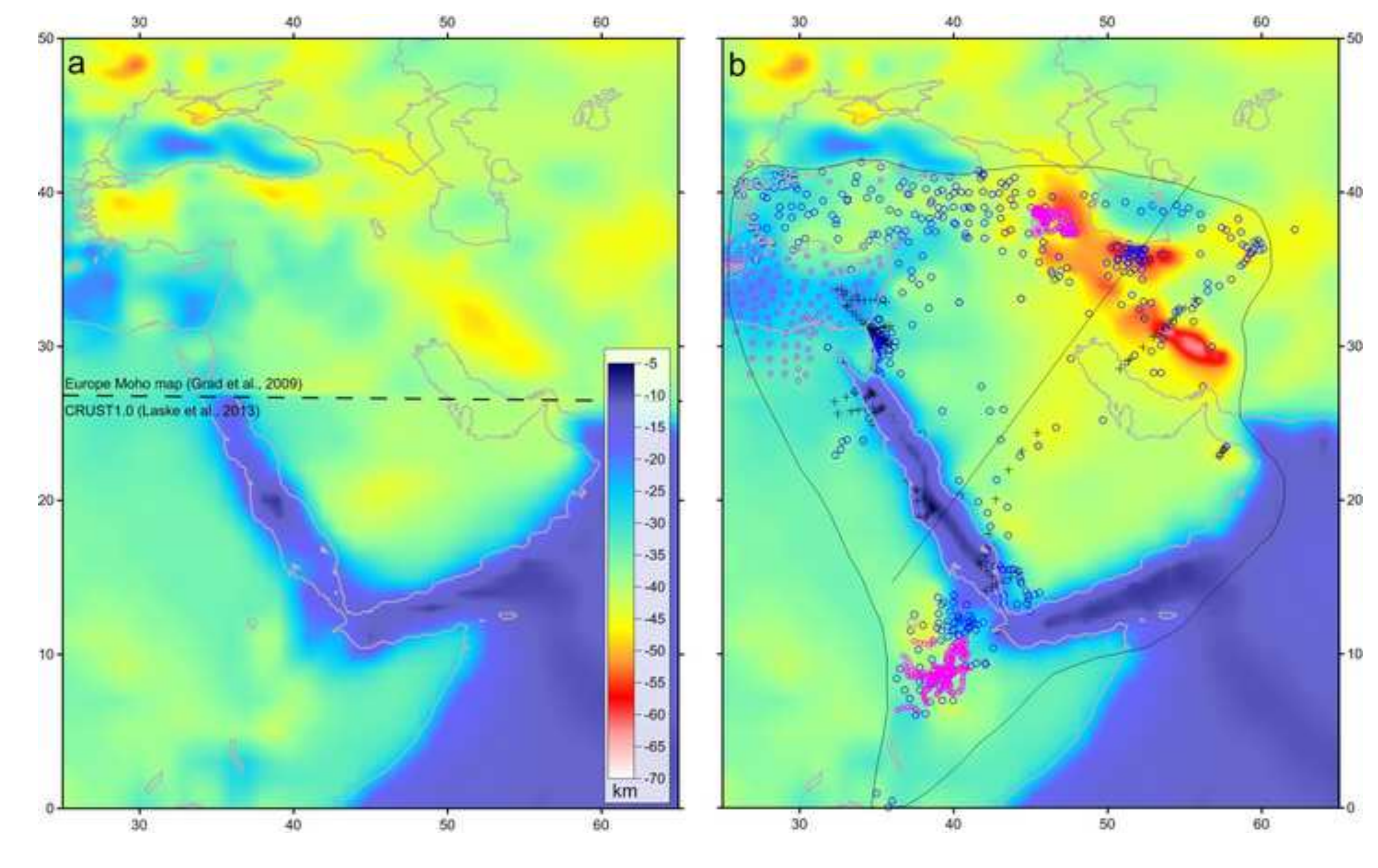

.

.



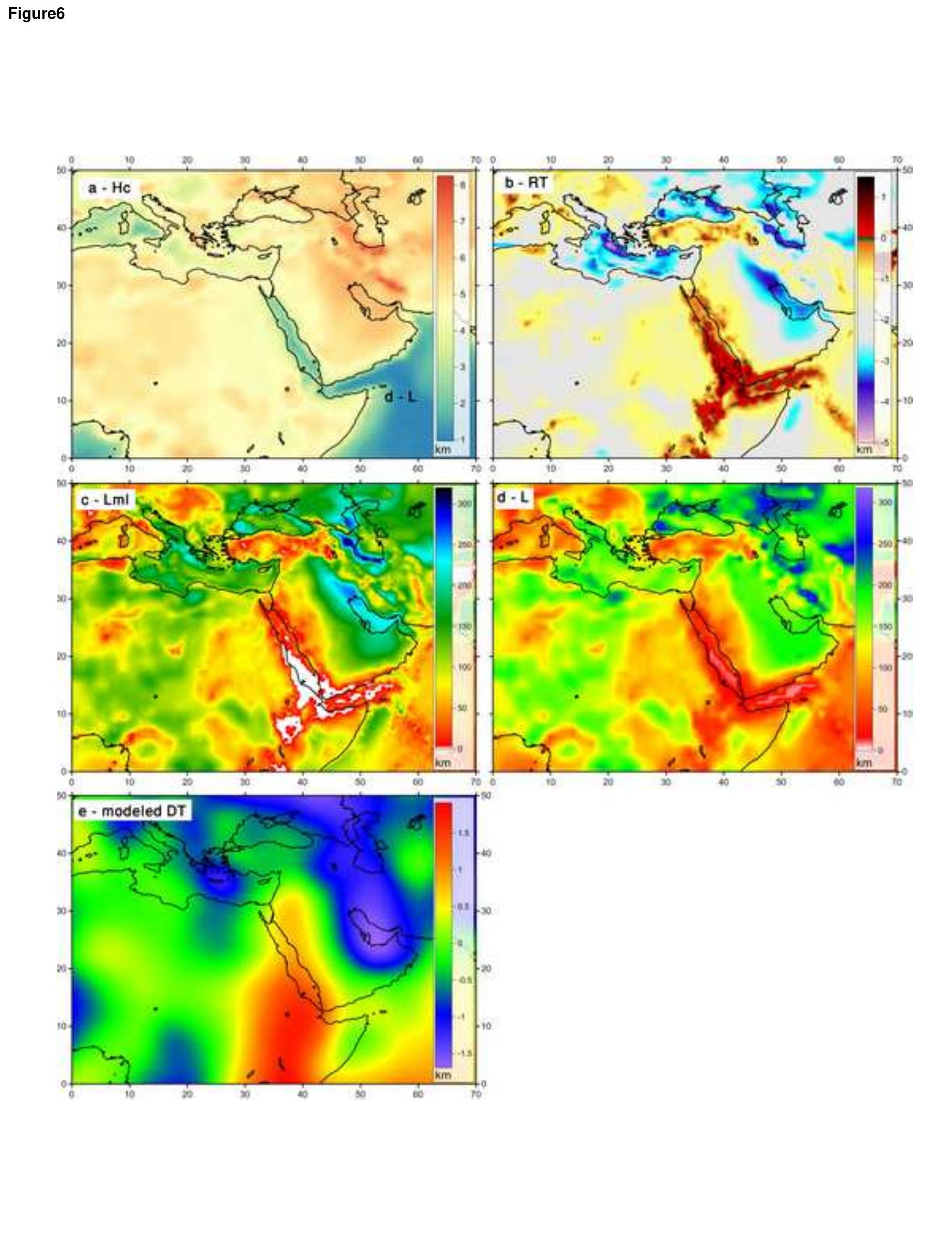

$$
\text { . }
$$

$$
\text { r. }
$$



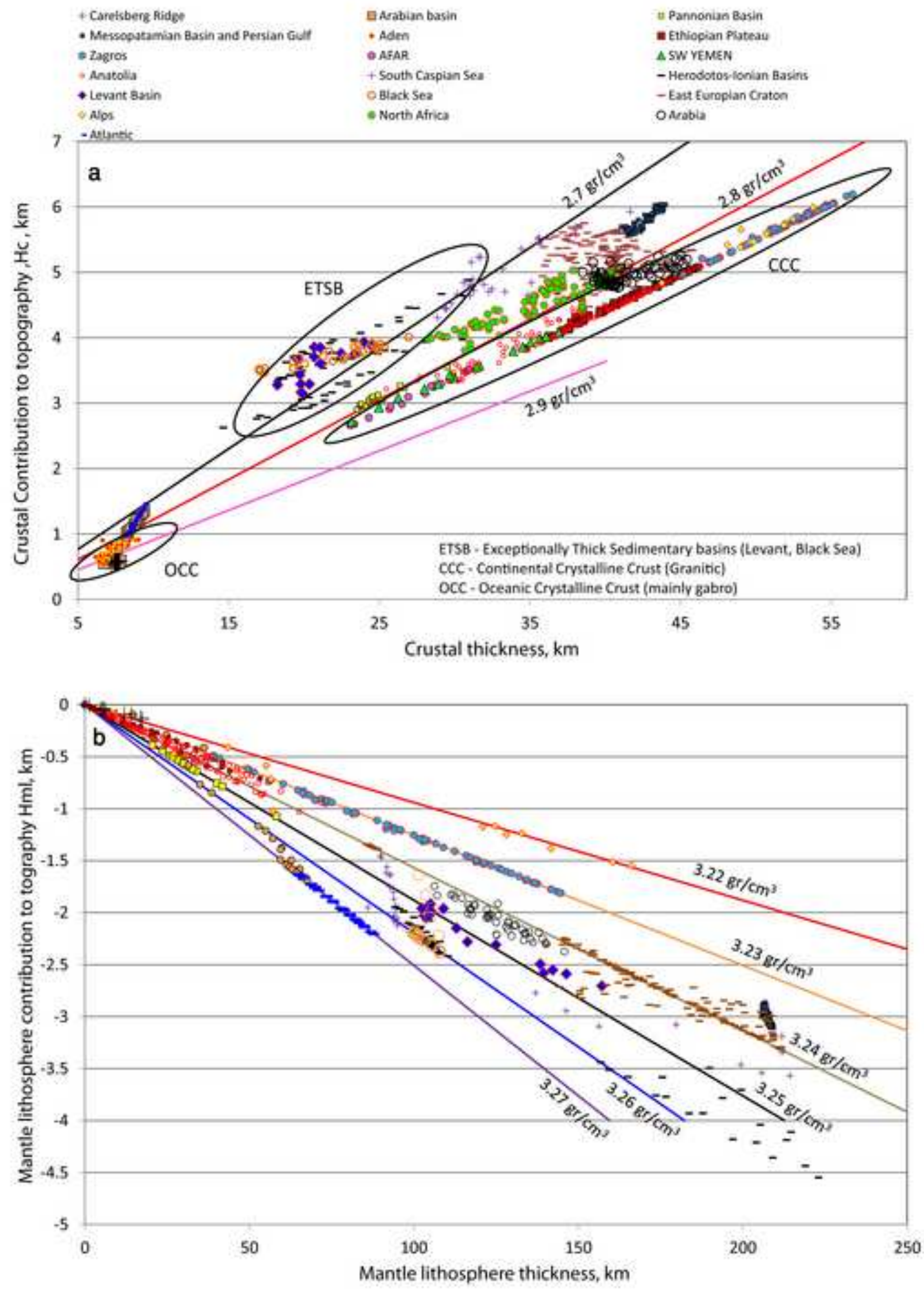

Figure7

s zagros

Alos
E Arabian basin

o afar

+ South Caspian Sea

2 Black Sea

North Afric: a Pannonian Basin

- Herodotosilonian Basins

- East Europian Craton

OArabla 

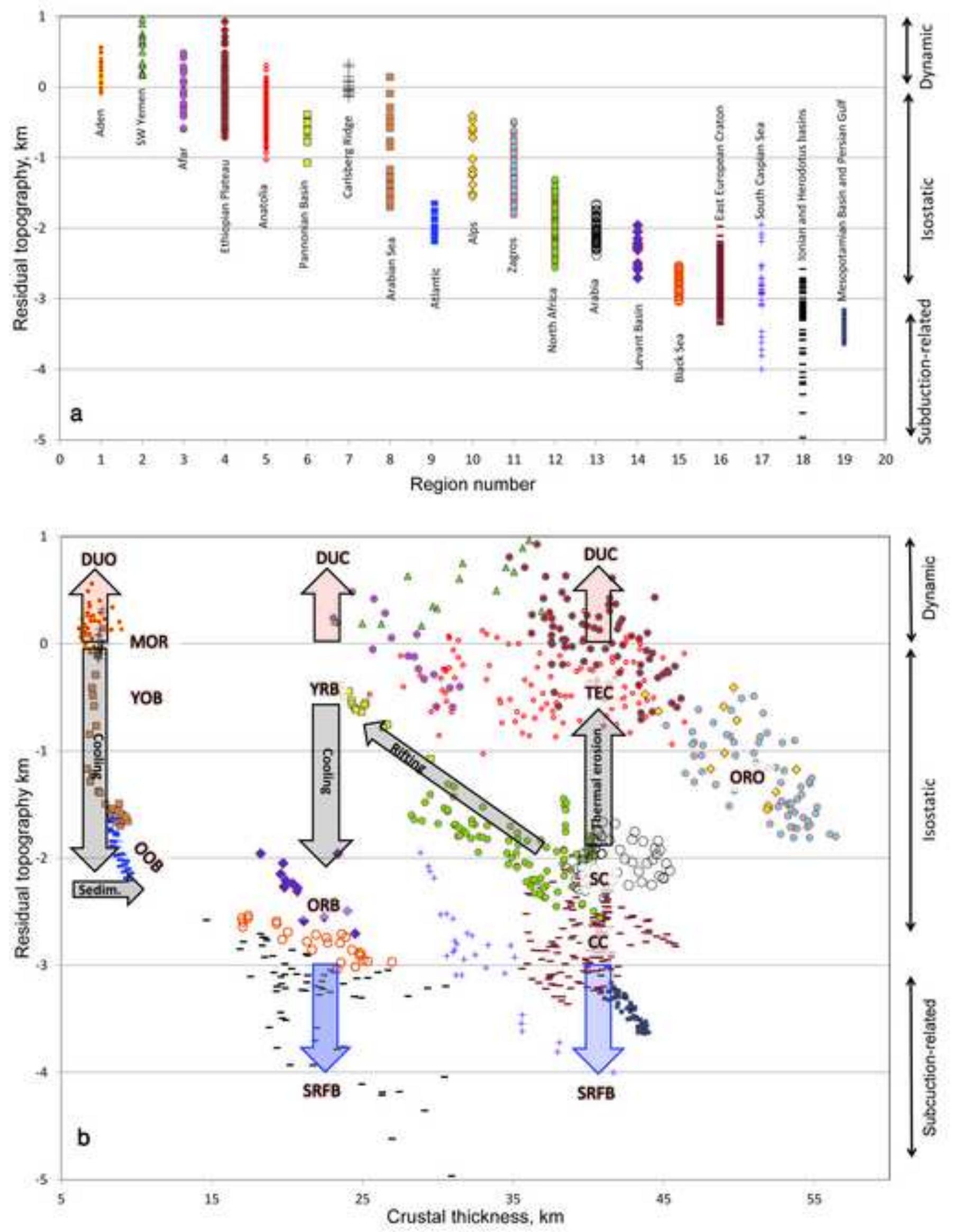

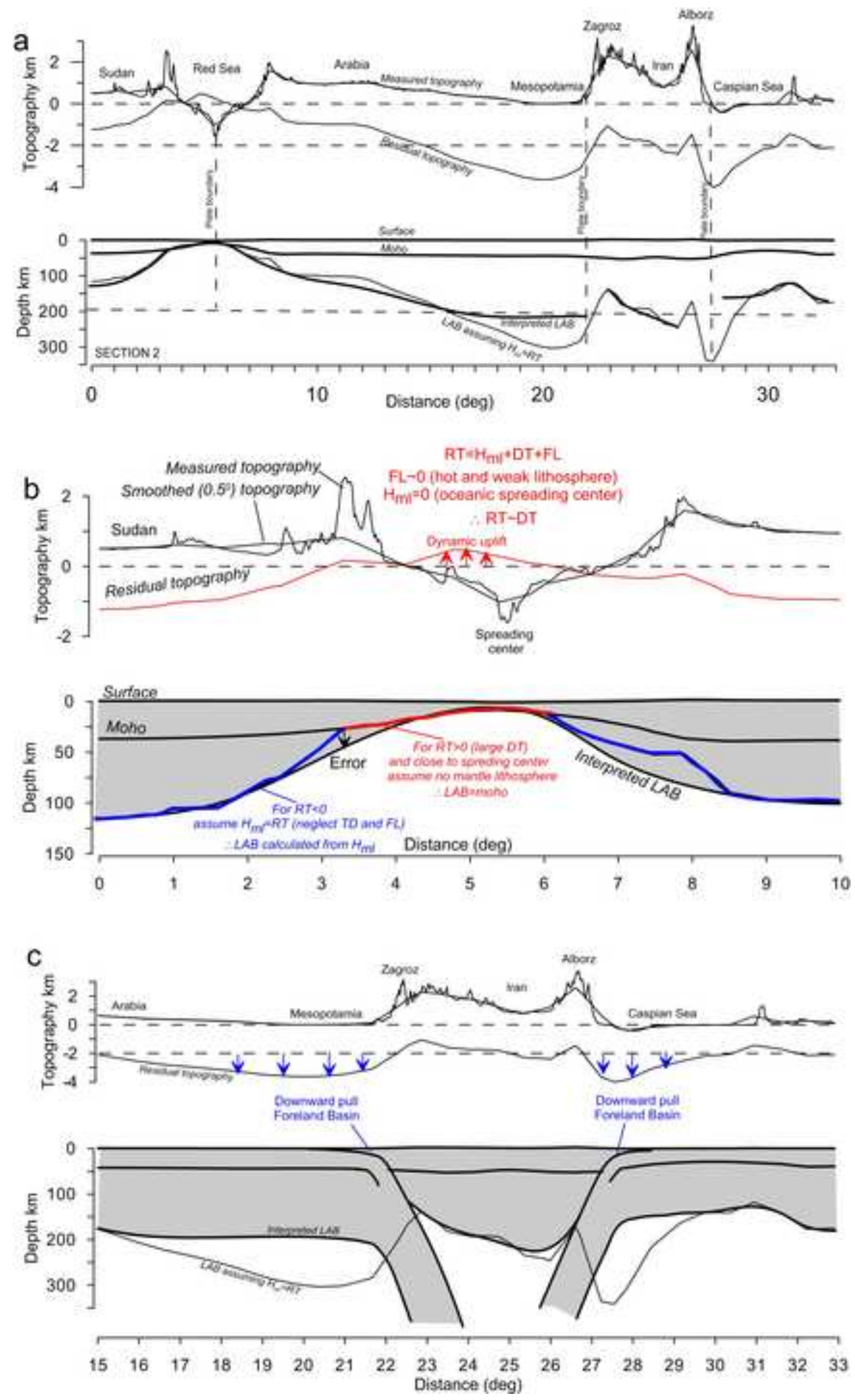

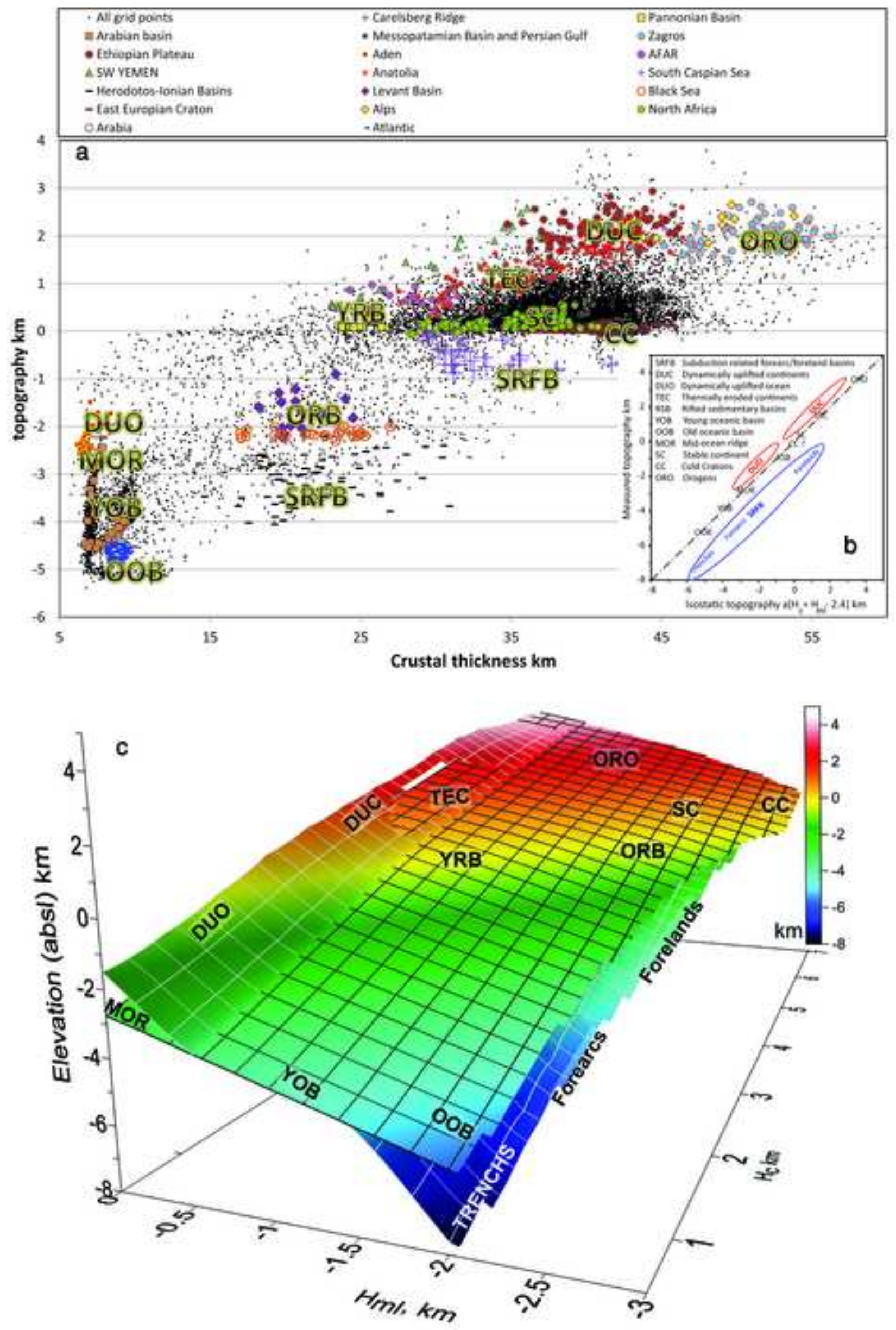


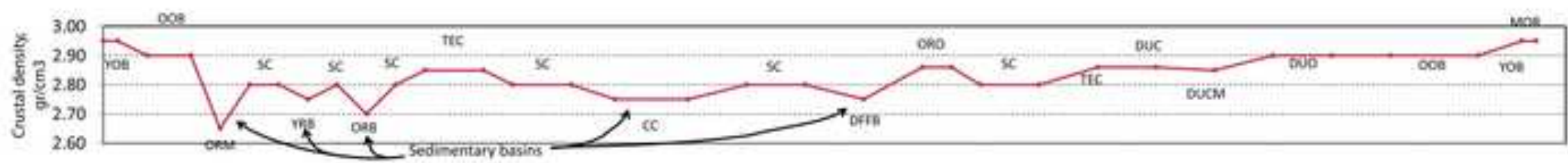

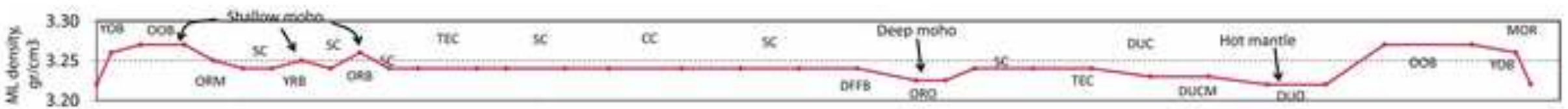
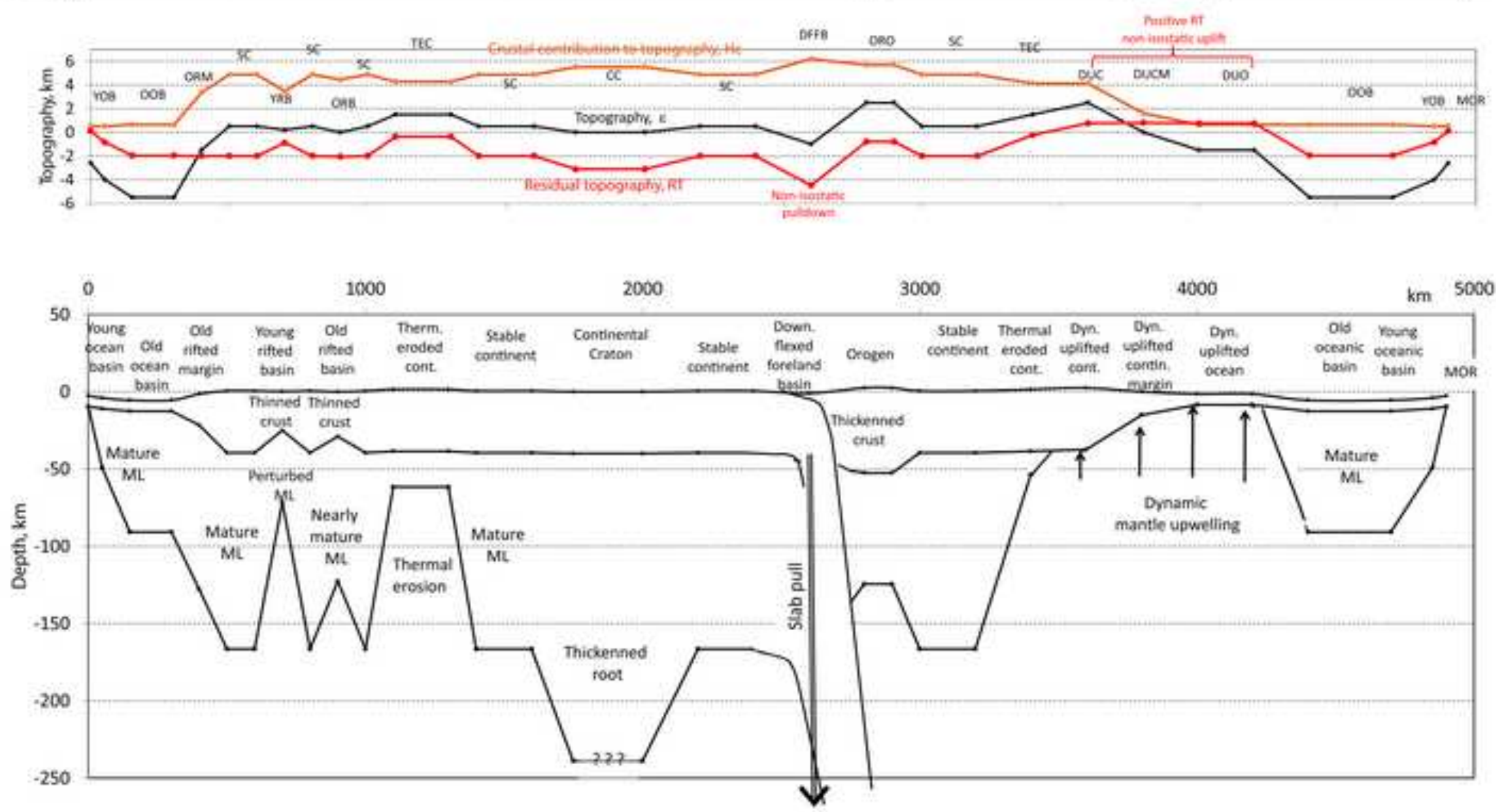